\title{
A Quantitative Description of Dendritic Conductances and Its Application to Dendritic Excitation in Layer 5 Pyramidal Neurons
}

\author{
Mara Almog and Alon Korngreen \\ The Leslie and Susan Gonda Interdisciplinary Brain Research Center, and The Mina and Everard Goodman Faculty of Life Sciences, Bar-Ilan University, \\ Ramat Gan 52900, Israel
}

Postsynaptic integration is a complex function of passive membrane properties and nonlinear activation of voltage-gated channels. Some cortical neurons express many voltage-gated channels, with each displaying heterogeneous dendritic conductance gradients. This complexity has hindered the construction of experimentally based mechanistic models of cortical neurons. Here we show that it is possible to overcome this obstacle. We recorded the membrane potential from the soma and apical dendrite of layer 5 (L5) pyramidal neurons of the rat somatosensory cortex. A combined experimental and numerical parameter peeling procedure was implemented to optimize a detailed ionic mechanism for the generation and propagation of dendritic spikes in neocortical L5 pyramidal neurons. In the optimized model, the density of voltage-gated $\mathrm{Ca}^{2+}$ channels decreased linearly from the soma, and leveled at the distal apical dendrite. The density of the small-conductance $\mathrm{Ca}^{2+}$-activated channel decreased along the apical dendrite, whereas the density of the large-conductance $\mathrm{Ca}^{2+}$-gated $\mathrm{K}^{+}$channel was uniform throughout the apical dendrite. The model predicted an ionic mechanism for the generation of a dendritic spike, the interaction of this spike with the backpropagating action potential, the mechanism responsible for the ability of the proximal apical dendrite to control the coupling between the axon and the dendrite, and the generation of NMDA spikes in the distal apical tuft. Moreover, in addition to faithfully predicting many experimental results recorded from the apical dendrite of L5 pyramidal neurons, the model validates a new methodology for mechanistic modeling of neurons in the CNS.

\section{Introduction}

Neurons in the CNS receive tens of thousands of synaptic inputs on their dendrites and integrate them to create an output in the form of action potentials (APs) that are relayed to the next neuron in the network. This synaptic information is shaped by the active and passive properties of the dendrites. APs initiated at or near the soma actively backpropagate into the dendritic tree (Stuart and Sakmann, 1994). Additionally, dendrites generate complex regenerative $\mathrm{Ca}^{2+}$ and $\mathrm{Na}^{+}$spikes (Schiller et al., 1997; Magee et al., 1998; Martina et al., 2000; Migliore and Shepherd, 2002; Johnston et al., 2003), and contain electrically and chemically defined compartments (Larkum et al., 1999b, 2001; 2009; Magee, 1999; Korngreen and Sakmann, 2000; Schiller et al., 2000). The exciting finding of regenerative activity in the apical dendrite of neocortical layer 5 (L5) pyramidal neurons (Schiller et al., 1997; Larkum et al., 1999a,b, 2001) has sparked renewed

\footnotetext{
Received July 8, 2013; revised 0ct. 21, 2013; accepted 0ct. 28, 2013.

Author contributions: M.A. and A.K. designed research; M.A. and A.K. performed research; M.A. and A.K. analyzed data; M.A. and A.K. wrote the paper.

This work was supported by Grant 212/07 from the Israel Science Foundation.

The authors declare no competing financial interests.

Correspondence should be addressed to Dr. Alon Korngreen, Mina and Everard Goodman Faculty of Life Sciences,

Leslie and Susan Gonda Multidisciplinary Brain Research Center, Bar-llan University, Ramat Gan 52900, Israel. E-mail: alon.korngreen@biu.ac.il.

DOI:10.1523/JNEUROSCI.2896-13.2014

Copyright $\odot 2014$ the authors $\quad 0270-6474 / 14 / 340182-15 \$ 15.00 / 0$
}

interest in the computational properties of single neurons (London and Häusser, 2005).

Current interpretations of neuronal physiology are based on the watershed investigation by Hodgkin and Huxley (1952) of APs in the giant squid axon. Thus, the golden path to the description of neuronal excitability passes through kinetic modeling of the voltage-gated channels expressed by the neuron, followed by the application of these models to a full numerical model of the neuron. This methodology can be hard to apply, since many CNS neurons express $>10$ types of ion channels that can display heterogeneous somatodendritic conductance gradients. Given this vast parameter space, compartmental models of single neurons in the CNS are notoriously difficult to tune, which has considerably restricted our ability to understand their integrative properties. Many models simply match specific experimental observations and are thus only crude approximations of neuronal physiology. Recently, numerical simulations have shown that multiple recordings of the membrane potential can be used to accurately constrain compartmental models. This can be achieved by using a simple gradient descent algorithm, if enough recording sites are available in the training dataset (Keren et al., 2005; Huys et al., 2006; Gold et al., 2007). Conversely, constraining a compartmental model solely by using somatic recordings of the membrane potential or reduced features of the dendritic membrane potential leads to the generation of a large solution manifold (Keren et al., 2005; Druckmann et al., 2007, 2008, 2011; Hay et al., 2011). Here we show that a dataset recorded from the soma and apical 
Table 1. Results of fitting the model to the data using a linear gradient for the MVA $\mathrm{Ca}^{2+}$ channel

\begin{tabular}{|c|c|c|c|c|c|c|c|c|c|c|c|}
\hline Parameter & Unit & Lower boundary & Upper boundary & Cell 1 & Cell 2 & Cell 3 & Cell 4 & Cell 5 & Average & SD & $\mathrm{CV}$ \\
\hline Distance & $\mu \mathrm{m}$ & & & 415 & 580 & 417 & 445 & 413 & 454 & 72 & \\
\hline $\mathrm{R}_{\mathrm{a}}$ & $\Omega \mathrm{cm}$ & 90 & 230 & 106 & 90 & 70 & 91 & 120 & 96 & 19 & 0.20 \\
\hline$R_{m}^{a}$ & $\Omega \mathrm{cm}^{2}$ & 3000 & 42,000 & 27,673 & 17,141 & 12,569 & 8374 & 25,812 & 18,314 & 8322 & 0.45 \\
\hline$C_{m}$ & $\mu \mathrm{F} / \mathrm{cm}^{2}$ & 0.5 & 1.8 & 0.79 & 0.59 & 0.81 & 0.60 & 0.60 & 0.68 & 0.11 & 0.16 \\
\hline $\mathrm{E}_{\text {passive }}$ & $\mathrm{mV}$ & -50 & -30 & -49.1 & -47.6 & -49.9 & -46.8 & -47.8 & -48.3 & 1.3 & 0.03 \\
\hline $\mathrm{G}_{\mathrm{lh} \text {, dend }}$ & $\mathrm{pS} / \mu \mathrm{m}^{2}$ & 90 & 210 & 92 & 114 & 92 & 159 & 118 & 115 & 28 & 0.24 \\
\hline$I_{\mathrm{h}, \mathrm{X} 1 / 2}$ & $\mu \mathrm{m}$ & 350 & 650 & 385 & 498 & 407 & 452 & 352 & 419 & 57 & 0.14 \\
\hline$I_{\mathrm{h}, \text { slope }}$ & $1 / \mu \mathrm{m}$ & -0.2 & -0.01 & -0.011 & -0.016 & -0.019 & -0.021 & -0.014 & -0.016 & 0.004 & 0.26 \\
\hline $\mathrm{G}_{\mathrm{lh}, \text { soma }}$ & $\mathrm{pS} / \mu \mathrm{m}^{2}$ & 1 & 3.5 & 1.31 & 3.49 & 1.09 & 2.77 & 2.51 & 2.24 & 1.01 & 0.45 \\
\hline $\mathrm{G}_{\mathrm{K} \text {, dend }}$ & $\mathrm{pS} / \mu \mathrm{m}^{2}$ & 3 & 15 & 4.79 & 3.65 & 14.46 & 3.93 & 3.79 & 6.13 & 4.68 & 0.76 \\
\hline $\mathrm{K}_{\mathrm{s}, \mathrm{slope}}$ & $1 / \mu \mathrm{m}$ & -0.1 & -0.02 & -0.071 & -0.060 & -0.085 & -0.081 & -0.092 & -0.078 & 0.012 & 0.16 \\
\hline$G_{K s, \text { soma }}$ & $\mathrm{pS} / \mu \mathrm{m}^{2}$ & 60 & 290 & 163 & 224 & 251 & 258 & 206 & 220 & 38 & 0.17 \\
\hline $\mathrm{G}_{\mathrm{Kf}, \mathrm{d} \text { dend }}$ & $\mathrm{pS} / \mu \mathrm{m}^{2}$ & 5 & 30 & 24 & 31 & 35 & 21 & 28 & 28 & 6 & 0.20 \\
\hline $\mathrm{K}_{\mathrm{f} \text {.slope }}$ & $1 / \mu \mathrm{m}$ & -0.1 & -0.005 & -0.020 & -0.008 & -0.030 & -0.020 & -0.012 & -0.018 & 0.009 & 0.48 \\
\hline $\mathrm{G}_{\mathrm{kf}, \text { soma }}$ & $\mathrm{pS} / \mu \mathrm{m}^{2}$ & 70 & 320 & 248 & 298 & 248 & 347 & 332 & 294 & 46 & 0.16 \\
\hline $\mathrm{G}_{\mathrm{Na} \text {,soma }}$ & $\mathrm{pS} / \mu \mathrm{m}^{2}$ & 150 & 600 & 222 & 507 & 187 & 150 & 352 & 284 & 146 & 0.52 \\
\hline $\mathrm{G}_{\mathrm{Na} \text {,dend }}$ & $\mathrm{pS} / \mu \mathrm{m}^{2}$ & 65 & 150 & 148 & 66 & 57 & 79 & 56 & 81 & 38 & 0.47 \\
\hline $\mathrm{Na}_{\text {dist }}$ & $\mu \mathrm{m}$ & 400 & 700 & 669 & 695 & 584 & 489 & 481 & 583 & 99 & 0.17 \\
\hline $\mathrm{Na}_{\text {shift,act }}$ & $\mathrm{mV}$ & -11 & -9 & -10.2 & -10.9 & -9.3 & -9.0 & -11.0 & -10.1 & 0.9 & 0.09 \\
\hline $\mathrm{Na}_{\text {shift,inact }}$ & $\mathrm{mV}$ & -11 & -9 & -11.0 & -9.9 & -10.8 & -10.0 & -9.6 & -10.2 & 0.6 & 0.06 \\
\hline$P_{\text {HVA,soma }}$ & $\mu \mathrm{m} / \mathrm{s}$ & 0 & 500 & 11.9 & 31.0 & 151.1 & 139.4 & 0.9 & 66.9 & 72.5 & 1.08 \\
\hline$P_{H V A, d e n d}$ & $\mu \mathrm{m} / \mathrm{s}$ & 0 & 500 & 0.06 & 1.65 & 2.48 & 1.17 & 1.56 & 1.39 & 0.88 & 0.64 \\
\hline $\mathrm{Ca}_{\mathrm{HVA}, \mathrm{dist}}$ & $\mu \mathrm{m}$ & 0 & 990 & 145 & 44 & 101 & 13 & 10 & 63 & 59 & 0.93 \\
\hline $\mathrm{Ca}_{\mathrm{HVA} \text {, shift,act }}$ & $\mathrm{mV}$ & -13 & 10 & -10.1 & -11.8 & -8.6 & -9.3 & -4.5 & -8.8 & 2.7 & 0.31 \\
\hline $\mathrm{Ca}_{\mathrm{HVA} \text {, shift,inact }}$ & $\mathrm{mV}$ & -13 & 10 & 1.9 & 7.0 & 3.5 & -1.1 & -7.1 & 0.8 & 5.3 & 6.40 \\
\hline$P_{M V A, s o m a}$ & $\mu \mathrm{m} / \mathrm{s}$ & 0 & 200 & 0.05 & 108.3 & 81.5 & 140.8 & 31.5 & 72.4 & 56.9 & 0.79 \\
\hline $\mathrm{P}_{\mathrm{MVA} \text {,dend }}$ & $\mu \mathrm{m} / \mathrm{s}$ & 0 & 200 & 11.3 & 10.1 & 30.3 & 10.1 & 4.9 & 13.3 & 9.8 & 0.73 \\
\hline $\mathrm{Ca}_{\mathrm{MVA}, \mathrm{dist}}$ & $\mu \mathrm{m}$ & 0 & 990 & 214 & 602 & 609 & 88 & 925 & 487 & 337 & 0.69 \\
\hline$C \mathrm{C}_{\mathrm{MVA}, \text { shift,act }}$ & $\mathrm{mV}$ & -10 & 10 & -9.8 & -9.8 & -2.9 & -9.9 & -9.7 & -8.4 & 3.1 & 0.36 \\
\hline $\mathrm{Ca}_{\mathrm{MVA}}$,shift,inact & $\mathrm{mV}$ & -15 & 10 & 0.6 & -5.0 & 4.9 & -11.2 & -2.1 & -2.6 & 6.1 & 2.37 \\
\hline $\mathrm{G}_{\mathrm{SK}, \text { soma }}$ & $\mathrm{pS} / \mu \mathrm{m}^{2}$ & 0 & 4 & 1.85 & 3.33 & 3.62 & 3.25 & 3.18 & 3.05 & 0.69 & 0.23 \\
\hline $\mathrm{G}_{\mathrm{SK}, \text { dend }}$ & $\mathrm{pS} / \mu \mathrm{m}^{2}$ & 0 & 4 & 0.36 & 1.23 & 1.10 & 0.06 & 0.52 & 0.65 & 0.50 & 0.76 \\
\hline $\mathrm{SK}_{\text {dist }}$ & $\mu \mathrm{m}$ & 0 & 900 & 401 & 580 & 677 & 367 & 239 & 453 & 175 & 0.39 \\
\hline $\mathrm{G}_{\mathrm{BK} \text {,soma }}$ & $\mathrm{pS} / \mu \mathrm{m}^{2}$ & 0 & 4 & 3.54 & 1.29 & 0.93 & 3.23 & 0.64 & 1.93 & 1.36 & 0.70 \\
\hline $\mathrm{G}_{\mathrm{BK} \text {,dend }}$ & $\mathrm{pS} / \mu \mathrm{m}^{2}$ & 0 & 4 & 0.53 & 3.51 & 3.87 & 0.13 & 1.23 & 1.85 & 1.73 & 0.93 \\
\hline $\mathrm{BK}_{\text {dist }}$ & $\mu \mathrm{m}$ & 0 & 900 & 16 & 104 & 269 & 4 & 28 & 84 & 111 & 1.31 \\
\hline
\end{tabular}

Parameter values obtained by constraining the model of the apical dendrite of $L 5$ pyramidal neurons using five experimental datasets. The distance of the dendritic pipette from the soma is noted in the top row. The average parameter value $(n=5)$, the SD, and the $C V$ are presented for each parameter. The passive parameters are the $R_{\mathrm{m}}$, the axial resistance $\left(R_{\mathrm{a}}\right)$, the membrane capacitance $\left(C_{\mathrm{m}}\right)$, and the passive reversal potential $\left(\mathrm{E}_{\text {passive }}\right)$. The dendritic conductance gradient of $I_{\mathrm{h}}$ was calculated using $G_{\mathrm{th}}(x)=G_{\mathrm{lh}, \mathrm{soma}}+G_{\mathrm{lh}, \text { end }} /\left(1+\exp \left(I_{\mathrm{h} \text {,shope }}\left(x-I_{\mathrm{h}, \mathrm{x} / 2}\right)\right)\right)$ (where $x$ stands for the distance from the soma along the apical dendrite). The dendritic conductance gradient of $\mathrm{K}_{\mathrm{s}}$ was calculated using the exponential equation $G_{\mathrm{Ks}}(x)=G_{\mathrm{Ks} \text {,dend }}+F_{\mathrm{Ks}, \text { soma }}\left(\exp \left(K_{\mathrm{s}, \text { slope }} \cdot x\right)\right.$ ). This formula was also used to calculate the dendritic conductance gradient of $\mathrm{K}_{\mathrm{f}}$. The dendritic conductance gradient of $\mathrm{Na}^{+}{ }^{+}$was calculated using $G_{\mathrm{Na}}(x)=G_{\mathrm{Na}, \text { soma }}+x\left(G_{\mathrm{Na} \text {,dend }}-G_{\mathrm{Na} \text {,soma }}\right) / \mathrm{Na}_{\mathrm{dist}}$. This formula was also used to calculate the dendritic permeability gradient of $\mathrm{Ca}_{\mathrm{HVA}}$ and $\mathrm{Ca}_{\mathrm{MVA}}$, and the dendritic conductance gradient of $\mathrm{SK}$ and $\mathrm{BK}$.

dendrite combined with a pharmacological and numerical parameter peeling procedure is sufficient to constrain a compartmental model for the apical dendrite of L5 pyramidal neurons containing eight channels. This model faithfully predicts a wide range of physiological activity recorded from L5 pyramidal neurons; it also provides a quantitative mechanism for assessing regenerative dendritic spiking in these neurons.

\section{Materials and Methods}

Slice preparation. Acute brain slices (sagittal, $300 \mu \mathrm{m}$ thick) were prepared from the somatosensory cortex of 30- to 35-d-old Wistar rats of either sex. The animals were killed by rapid decapitation after shallow anesthesia with isoflurane (Stuart et al., 1993) following the guidelines of the Bar-Ilan University animal welfare committees. Slices were perfused throughout the experiment with oxygenated artificial CSF (ACSF) containing the following (in $\mathrm{mm}$ ): $125 \mathrm{NaCl}, 15 \mathrm{NaHCO}_{3}, 2.5 \mathrm{KCl}, 1.25$ $\mathrm{NaH}_{2} \mathrm{PO}_{4}, 1 \mathrm{MgCl}_{2}, 2 \mathrm{CaCl}_{2}$, and 25 glucose, $\mathrm{pH} 7.4$ with $5 \% \mathrm{CO}_{2}$ at $32-34^{\circ} \mathrm{C}$. The bath solution for the current-clamp experiments in which all $\mathrm{Ca}^{2+}$-gated $\mathrm{K}^{+}$channels were blocked contained the following (in mM): $135 \mathrm{NaCl}, 15 \mathrm{HEPES}, 2.5 \mathrm{KCl}, 1 \mathrm{MgCl}_{2}, 2 \mathrm{CaCl}_{2}, 25$ glucose, $1 \mathrm{~mm}$ tetraethylammonium (TEA; Sigma), pH 7.4 with $\mathrm{NaOH}$. Apamin (Alomone Labs) and iberiotoxin (Alomone Labs) were stored at $-20^{\circ} \mathrm{C}$ as stock solutions in double-distilled water and added directly to the bath solution to form final concentrations of 200 and $30 \mathrm{~nm}$, respectively.
Before adding iberiotoxin to the bath solution, the perfusion tubing was coated with Sigmacote (Sigma) to prevent binding of the toxin. In addition, in experiments with iberiotoxin, $0.1 \mathrm{mg} / \mathrm{ml}$ bovine serum albumin (Sigma) was added to the application solution to prevent nonspecific binding by the iberiotoxin.

Electrophysiology. Pyramidal neurons from L5 were visually identified using infrared differential interference contrast videomicroscopy (Stuart et al., 1993). Patch pipettes (4-7 M $\Omega$ somatic, 7-12 $M \Omega$ dendritic) were pulled from thick-walled borosilicate glass capillaries $(2.0 \mathrm{~mm}$ outer diameter, $0.5 \mathrm{~mm}$ wall thickness; Hilgenberg). The standard pipette solution contained the following (in $\mathrm{mm}$ ): $125 \mathrm{~K}$-gluconate, $20 \mathrm{KCl}, 10$ HEPES, 4 MgATP, 10 Na-phosphocreatin, 0.5 EGTA, 0.3 GTP, and $0.2 \%$ biocytin, $\mathrm{pH} 7.2$ with $\mathrm{KOH}$. A liquid junction potential of $10 \mathrm{mV}$ was not corrected for. Whole-cell recordings from the soma and apical dendrite were performed at $36-38^{\circ} \mathrm{C}$ using a Multiclamp-700B amplifier (Molecular Devices). Voltage was filtered at $10 \mathrm{kHz}$ and sampled at 50 or $20 \mathrm{kHz}$ using AxoClamp9 (Molecular Devices), digitized by a Digidata-1320 interface (Molecular Devices), and stored on the hard disk of a personal computer. At the end of each experiment, slices were fixed in cold 100 mм PBS, pH 7.4, containing 4\% paraformaldehyde. After fixation, the slices were incubated for $2 \mathrm{~h}$ in avidin-biotinylated horseradish peroxidase (ABC-Elite, Vector Laboratories), and the stain was developed using $0.015 \%$ diaminobenzidine. The stained neurons were digitally traced using a Neurolucida system (MicroBrightField), and the tracings were 
converted to NEURON readable code. Care was taken that, in NEURON, no compartment exceeded $50 \mu \mathrm{m}$ in length.

Numerical simulations. The compartmental model, genetic algorithm, and cost function were programmed using NEURON version 5.9 (Carnevale and Hines, 2006). Simulations were run on a custom-made Linux cluster with 168 central processing units sharing the same network file system. One of the machines functioned as a master, submitting and managing the jobs using the ParallelContext class of NEURON over a MPICH2 ring spanning the other computers. Ion channel models were implemented using the NMODL extension of NEURON (Carnevale and Hines, 2006). All simulations were performed with an integration time step of $50 \mu \mathrm{s}$.

Compartmental model. We slightly modified our previous model and applied the assumptions used in the study by Keren et al. (2009), where full details are given. The assumptions were as follows: the morphology of the neuron is known; the passive membrane parameters are spatially uniform; and intracellular $\mathrm{Ca}^{2+}$ dynamics were simulated as a $\mathrm{Ca}^{2+}$ extrusion by a CaATPase (Destexhe et al., 1993), in which the decay time constant could be viewed as a simple intracellular $\mathrm{Ca}^{2+}$ buffer:

$$
[\mathrm{Ca}]_{i}=-\left(\frac{I_{\mathrm{Ca}} k}{2 \mathrm{Fd}}\right)+\frac{[\mathrm{Ca}]_{\text {rest }}-[\mathrm{Ca}]}{\tau},
$$

where $\left[\mathrm{Ca}^{2+}\right]_{\mathrm{i}}$ is in millimoles, the unit conversion constant is $k=10,000$ for $I_{\mathrm{Ca}}$ (in microamperes per square centimeter), $F=96489$ $\mathrm{C} / \mathrm{mol}$ is the Faraday constant, $d=0.1 \mu \mathrm{m}$ is the depth of the shell beneath the membrane, $\left[\mathrm{Ca}^{2+}\right]_{\text {rest }}=10^{-5} \mathrm{~mm}$ is the intracellular $\mathrm{Ca}^{2+}$ concentration at rest, $\left[\mathrm{Ca}^{2+}\right]$ is the change in the $\mathrm{Ca}^{2+}$ concentration during an event, and $\tau=80 \mathrm{~ms}$ is the rate of $\mathrm{Ca}^{2+}$ removal that was adapted to cortical neurons (Schaefer et al., 2003); the model contained eight voltage- and $\mathrm{Ca}^{2+}$-gated ion channels. These included an $\mathrm{Na}^{+}$channel, a slow inactivating $\mathrm{K}^{+}$channel, a fast inactivating $\mathrm{K}^{+}$channel, and a hyperpolarization-activated cation current $\left(I_{\mathrm{h}}\right)$ channel (Keren et al., 2005, 2009). Two voltage-gated $\mathrm{Ca}^{2+}$ channels, a high voltageactivated (HVA) $\mathrm{Ca}^{2+}$ channel and a medium voltage-activated (MVA) $\mathrm{Ca}^{2+}$ channel were based on nucleated patches (Almog and Korngreen, 2009) and whole-cell recordings (Foehring et al., 2000; Magistretti et al., 2000). The models of the voltage-gated $\mathrm{Ca}^{2+}$ channels were based on the Goldman-Hodgkin-Katz equation, which appeared to be more sensitive to the intracellular $\mathrm{Ca}^{2+}$ changes within the neuron. An MVA Ca ${ }^{2+}$ model with a slow inactivation time constant (in milliseconds) was chosen. Finally, two $\mathrm{Ca}^{2+}$-gated $\mathrm{K}^{+}$channels, a small-conductance $\mathrm{Ca}^{2+}$ gated $\mathrm{K}^{+}\left(\mathrm{K}_{\mathrm{SK}}\right)$ channel, and a large-conductance $\mathrm{Ca}^{2+}$-gated $\mathrm{K}^{+}$ channel $\left(K_{\mathrm{BK}}\right)$ were based on whole-cell recordings (Khaliq et al., 2003; Sun et al., 2003; Akemann and Knöpfel, 2006; Mercer et al., 2007; Deister et al., 2009). All the channels were modeled using models based on the study by Hodgkin and Huxley (1952). The units used in reporting the parameters are as follows: the permeability of the $\mathrm{Ca}^{2+}$ channels is given in micrometers per second; the conductance of the ion channels is given in picosiemens per square micrometer; the time constant is given in b

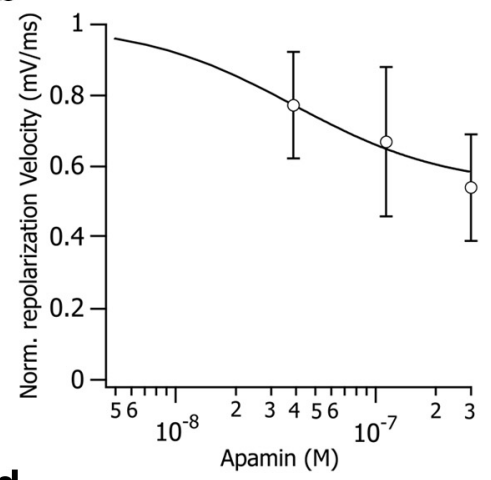

d

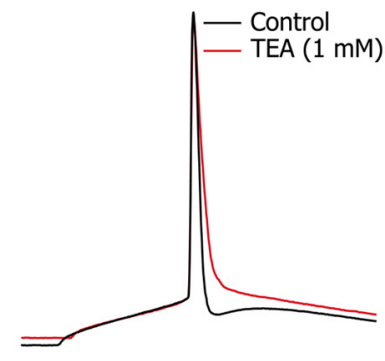

f

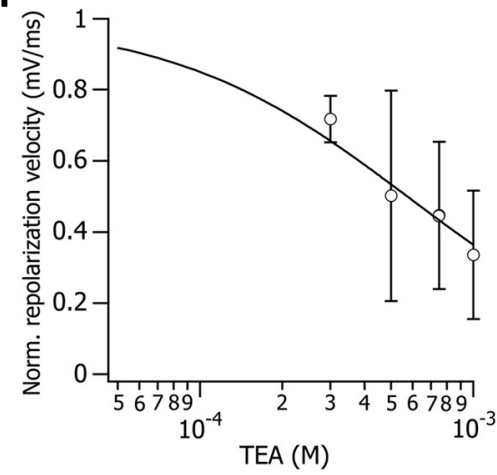

Figure 1. Pharmacological block of $\mathrm{Ca}^{2+}$-gated $\mathrm{K}^{+}$channels. $\boldsymbol{a}$, A somatic action potential measured from a $\mathrm{L} 5$ pyramidal neuron before (black trace) and after (red trace) adding apamin $(100 \mathrm{~nm})$ to the bath solution. $\boldsymbol{b}$, The relationship between apamin concentration and inhibition of the repolarizing velocity of the action potential plotted on a logarithmic concentration scale ( $n \geq$ 4). The repolarizing velocity was normalized to the minimal value. The data were fitted with the Hill equation (solid line), giving an $\mathrm{IC}_{50}$ of $30.82 \pm 5.89 \mathrm{~nm}$. Error bars indicate normalized SEM. C, A somatic action potential measured from a L5 pyramidal neuron before (black trace) and after (red trace) adding iberiotoxin ( $30 \mathrm{~nm})$ to the bath solution. $\boldsymbol{d}$, A somatic action potential measured from an L5 pyramidal neuron before (black trace) and after (red trace) adding TEA ( $1 \mathrm{~mm}$ ) to the bath solution. $\boldsymbol{e}$, Comparison of the repolarizing velocity of the action potential in the different bath solutions: control solution (ACSF, $n=9)$, solution containing TEA $(1 \mathrm{~nm}, n=4)$; and solution containing iberiotoxin $(30 \mathrm{~nm}, n=4)$. The asterisk indicates a significant difference $(p<0.00005$, one-tailed $t$ test) between the control solution and the solution containing TEA. The double asterisk indicates a significant difference ( $p<0.00005$, one-tailed $t$ test) between the control solution and the solution containing iberiotoxin. Error bars indicate SEM. $\boldsymbol{f}$, The relationship between TEA concentration and inhibition of the repolarizing velocity of the action potential plotted on a logarithmic concentration scale $(n=4)$ as in $\boldsymbol{b}$. The fit gave an $\mathrm{IC}_{50}$ of $0.58 \pm 0.046 \mathrm{mM}$. Errors bars indicate normalized SEM.

milliseconds; the membrane potential is given in millivolts; the permeability of the HVA Ca ${ }^{2+}$ channel $\left(\mathrm{Ca}_{\mathrm{HVA}}\right)$ is given as:

$$
\begin{gathered}
P_{\mathrm{CaHVA}}=\bar{P}_{\mathrm{CaHVA}} \alpha_{\infty}^{2} \beta_{\infty} \\
\alpha_{\infty}=1.1 /\left(1+\exp \left(-\left(V_{m}+14\right) / 10\right)\right) \\
\tau_{\alpha}=0.97 / \cosh \left(0.032\left(V_{m}+26\right)\right) ; \\
\beta_{\infty}=0.75 /\left(1+\exp \left(\left(V_{m}+23\right) / 7\right)\right) \\
\tau_{\beta}=70 / \cosh \left(0.047\left(V_{m}-20\right)\right)
\end{gathered}
$$


a

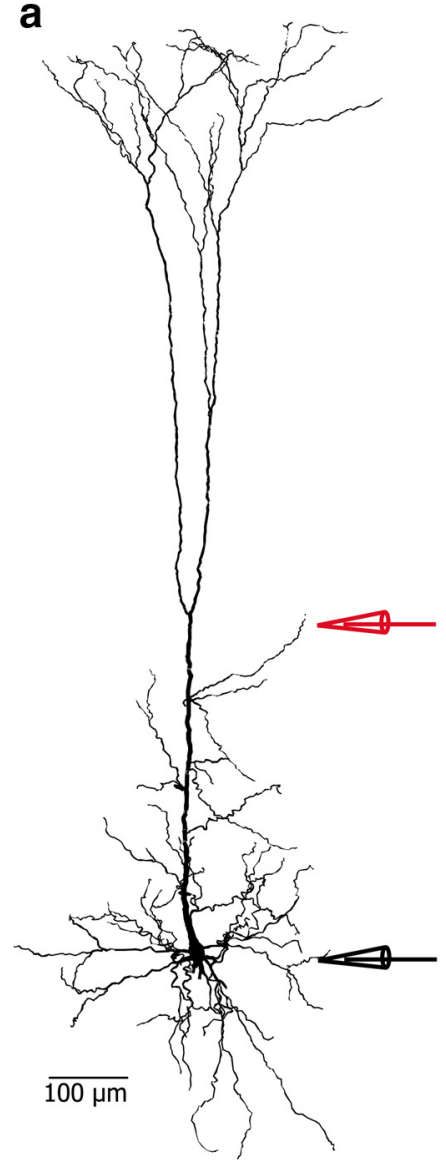

b A
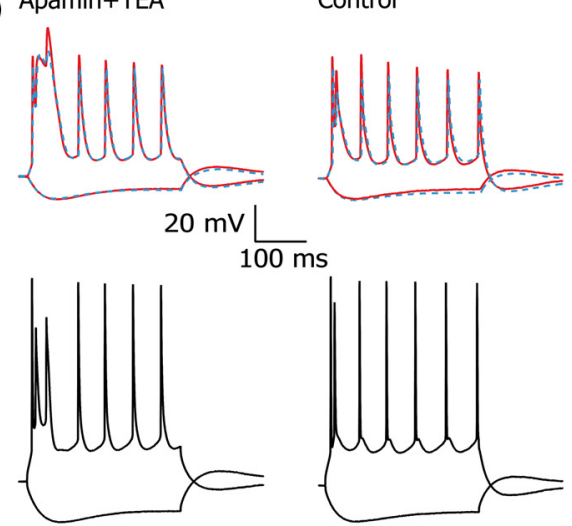

c
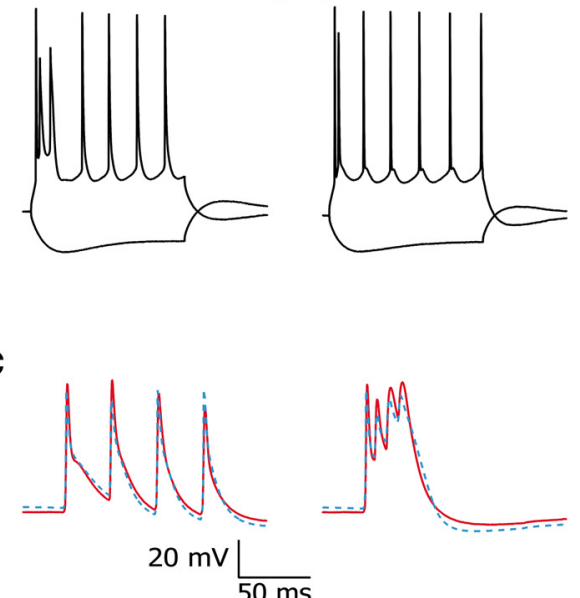

Figure 2. Application of the parameter peeling procedure to recordings from the apical dendrite of $L 5$ pyramidal neurons. $\boldsymbol{a}$, Reconstruction of a $L 5$ pyramidal neuron stained with biocytin illustrating electrode placement. $\boldsymbol{b}$, Constraining passive membrane parameters and channel density gradients of voltage-gated $\mathrm{K}^{+}, \mathrm{Na}^{+}, \mathrm{Ca}^{2+}$, and $/ \mathrm{h}$ channels (left), and $\mathrm{Ca}^{2+}$-gated $\mathrm{K}^{+}$channels (right). Hyperpolarizing and depolarizing membrane potential traces were recorded at the soma (black traces) and at $415 \mu \mathrm{m}$ along the apical dendrite (red traces). $\mathrm{Ca}^{2+}$-gated $\mathrm{K}^{+}$channels were blocked by apamin $(200 \mathrm{~nm})$ and TEA (1 mM). The dashed blue traces show the membrane potential traces simulated at the dendrite using the best parameter set obtained by the genetic algorithm. Table 1 (cell 1) shows the final parameter set obtained from this optimization. c, In a simulation, the somatic membrane potential of this cell was clamped to an experimental waveform series of four APs at 41 and $157 \mathrm{~Hz}$ that were recorded from cell 1 (black traces; Table 1). The membrane potential traces recorded at $415 \mu \mathrm{m}$ along the dendrite are shown in red. The dashed blue traces represent the membrane potential traces simulated at the dendrite using the best parameter set obtained by the genetic algorithm.

permeability of the MVA $\mathrm{Ca}^{2+}$ channel $\left(\mathrm{Ca}_{\mathrm{MVA}}\right)$ is given as:

$$
\begin{gathered}
P_{\mathrm{CaMVA}}=\bar{P}_{\mathrm{CaR}} \alpha_{\infty}^{2} \beta_{\infty} \\
\alpha_{\infty}=1 /\left(1+\exp \left(-\left(V_{m}+23\right) / 7\right)\right) \\
\tau_{\alpha}=5.5 / \cosh \left(0.032\left(V_{m}+23\right)\right) ; \\
\beta_{\infty}=1 /\left(1+\exp \left(\left(V_{m}+79\right) / 8\right)\right) \\
\tau_{\beta}=771 / \cosh \left(0.047\left(V_{m}+79\right)\right)
\end{gathered}
$$

conductance of the $\mathrm{K}_{\mathrm{SK}}$ channel is given as:

$$
\begin{gathered}
G_{\mathrm{KSK}}=\bar{G}_{\mathrm{KSK}} \alpha_{\infty} \\
\alpha=1.3^{4} \cdot\left[\mathrm{Ca}^{2+}\right]_{\mathrm{i}}^{4} ; \\
\alpha_{\infty}=\alpha /(\alpha+0.06) \\
\tau_{\alpha}=1 /(\alpha+0.06)
\end{gathered}
$$

conductance of the $\mathrm{K}_{\mathrm{BK}}$ channel is given as:

$$
G_{\mathrm{KBK}}=\bar{G}_{\mathrm{KBK}} \alpha_{\infty}^{3} \gamma^{2} \beta_{\infty}
$$

$$
\begin{gathered}
\alpha_{\infty}=1 /\left(1+\exp \left(-\left(V_{m}+29\right) / 6.2\right)\right) \\
\tau_{\alpha}=1000.505 /\left(\exp \left(-\left(\left(V_{m}+86\right) /-10\right)\right)\right) \\
\gamma_{\infty}=1 /\left(1+0.001 /\left[\mathrm{Ca}^{2+}\right]_{\mathrm{i}}\right. \\
\tau_{\gamma}=1 \\
\beta_{\infty}=0.085+(1-0.085) / \\
\left(1+\exp \left(-\left(V_{m}+32\right) /-6\right)\right) \\
\tau_{\beta}=1001.9 /\left(\exp \left(-\left(\left(V_{m}+49\right) / 13\right)\right)\right)
\end{gathered}
$$

and the kinetics of the channels are known and were based on experimental recordings.

Dendritic channel gradients were a continuous function of the distance from the soma. Reconstructed axons were removed. Where stated, the axon was replaced by an artificial axon (Mainen and Sejnowski, 1996; Schaefer et al., 2003) to allow AP initiation. In the myelinated axon, the membrane capacitance $\left(\mathrm{C}_{\mathrm{m}}\right)$ was reduced to $0.04 \mu \mathrm{F} / \mathrm{cm}^{2}$, and the passive membrane conductance $\left(G_{\text {passive }}\right)$ was changed to 0.02 $\mathrm{pS} / \mu \mathrm{m}^{2}$ in the nodes of Ranvier. Channel densities were as follows in the axon hillock initial segment in the node of Ranvier: $\mathrm{G}_{\mathrm{Na}}=30,000, \mathrm{G}_{\mathrm{Ks}}$ $=1500$, and $\mathrm{G}_{\mathrm{Kf}}=1000$ (where $\mathrm{G}_{\mathrm{Na}}, \mathrm{G}_{\mathrm{Ks}}$, and $\mathrm{G}_{\mathrm{Kf}}$ are the maximal conductances per unit area of the sodium, slow inactivating potassium, and fast inactivating potassium conductances, respectively). Channel densities were as follows in the myelinated axon: $G_{\mathrm{Na}}, G_{\mathrm{Ks}}$, and $G_{\mathrm{Kf}}$ as the soma (Table 1, cell 5). The full details of the basic model are given in (Keren et al., 2005, 2009). The reversal potentials of the voltage- and $\mathrm{Ca}^{2+}$. gated ion channels were set at $60,-80,130$, and $-30 \mathrm{mV}$, respectively, for $\mathrm{Na}^{+}, \mathrm{K}^{+}, \mathrm{Ca}^{2+}$, and $I_{\mathrm{h}}$. The NEURON code of the model and the genetic algorithm were donated to the ModelDB database.

Genetic algorithm. A genetic algorithm is an optimization algorithm based on the mechanisms of Darwinian evolution. It uses random mutation, crossover, and selection operators to breed better models or solutions (individuals) from an originally random starting population (Mitchell, 1996). The current study used a genetic algorithm similar to those used previously (Keren et al., 2005, 2009; Gurkiewicz and Korngreen, 2007). Briefly, the population was sorted according to the value of the cost function of each individual (Eq. 1), and a new generation was created using selection, crossover, and mutation as operators. Selection used a tournament in which two pairs of individuals were randomly selected and the individual with the better score from each pair was transferred to the next generation. This procedure was repeated $N / 2$ times (where $N$ is the size of the population) until the new population was full. The one exception to this selection process (and later to the crossover and mutation operators) was that the best individual was transferred unchanged to the next generation to prevent genetic drift.

Each pair selected for transfer to the new population was subjected to a one-point crossover operator with a probability of 0.5 . After the new population was created, each parameter value in the new population was subjected to mutation with a probability of 0.1 . The mutation operator performed a substitution of the parameter value with a random value drawn from a flat random number distribution spanning the entire search space of the parameter. On average, a typical run of the genetic algorithm lasted 2-3 d on our Linux cluster.

The cost function calculated the difference between the target and the test membrane potential traces, and summed its mean squares, yielding a 
cost function value expressing the distance of the test from the target dataset, as follows:

$$
\Psi^{2}=\frac{1}{M N} \sum_{i}^{M} \sum_{j}^{N}\left(V_{i, j}-v_{i, j}\right)^{2},
$$

where $V$ represents the target dataset, and $v$ represents the membrane potential changes in the test dataset. $N$ is the total number of points in each membrane potential trace, and $M$ is the number of membrane potential sweeps simulated in the model or recorded in the experiment.

Data analysis. Data were analyzed using IgorPro and Excel software. The influence of the blockers on the membrane potential was examined by fitting a linear function to the repolarization phase of a single AP. This fit gave the repolarizing velocity for the three different blockers and each concentration used. For each blocker, the repolarizing velocity was normalized to the control value. The normalized repolarizing velocity was plotted versus the log concentration of each blocker. The $\mathrm{IC}_{50}$ values were calculated using the following equation:

$$
D=1-\left(\frac{(1-\text { base }) \cdot[\text { blocker }]}{[\text { blocker }]+\left[\mathrm{IC}_{50}\right]}\right),
$$

where $\Delta$ is the relative repolarizing velocity change, base is the normalized repolarizing velocity value of the bottom plateau of the curve itself, blocker is the blocker concentration, and $\mathrm{IC}_{50}$ is for the blocker. The voltage time integral was calculated for simulated dendritic EPSPs and spikes to compare the response to simultaneous activation of NMDA and AMPA synapses (Larkum et al., 2009; ModelDB accession no. 124043) to the expected response (summation of individual activation of the synapses).

Statistical analysis. The statistical analysis used a one-tailed Student's $t$ test $\left({ }^{*},{ }^{* *} p<\right.$ $0.00005)$. All values are displayed as the mean \pm SE, unless otherwise stated. The coefficient of variation (CV) was calculated for each parameter in the model. The confidence limits for the mean gradients were calculated with a significance level of $0.1(\alpha)$.

\section{Results}

Blocking all voltage-gated $\mathrm{Ca}^{2+}$ channels by substituting the $\mathrm{Ca}^{2+}$ bath with $\mathrm{Co}^{2+}$ (Keren et al., 2009) previously enabled us to reduce the parameter space in a model of L5 neocortical pyramidal neurons. Using somatodendritic recordings obtained under these conditions allowed a genetic optimization algorithm to constrain a simple model for the apical dendrite of L5 pyramidal neurons in several optimization steps (Keren et al., 2009). Here we extended this pharmacological parameter peeling procedure to constrain a full model for the apical dendrite of L5 pyramidal neurons. We designed the current-clamp recordings required to obtain a new dataset isolating the effect of the voltage-gated $\mathrm{Ca}^{2+}$ channels during a $\mathrm{Ca}^{2+}$ spike by blocking all the subtypes of $\mathrm{Ca}^{2+}$-gated $\mathrm{K}^{+}$channels. First, pharmacological experiments determined the required concentration of blockers of the $\mathrm{Ca}^{2+}$ gated $\mathrm{K}^{+}$channels. Figure $1 a$ shows the effect of $100 \mathrm{~nm}$ apamin, limits of the average. b

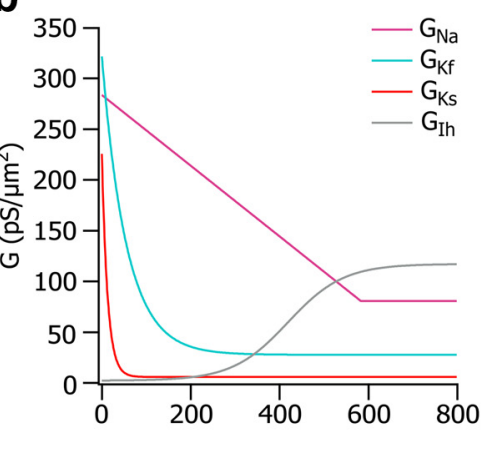

d

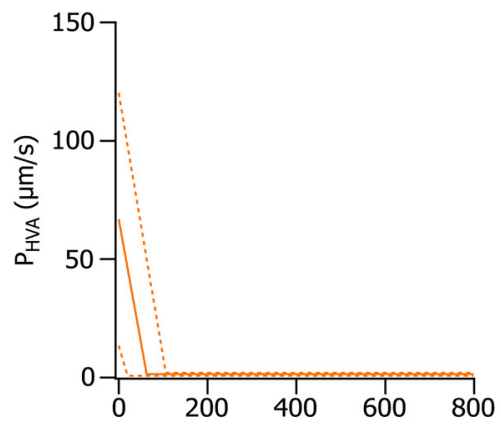

f

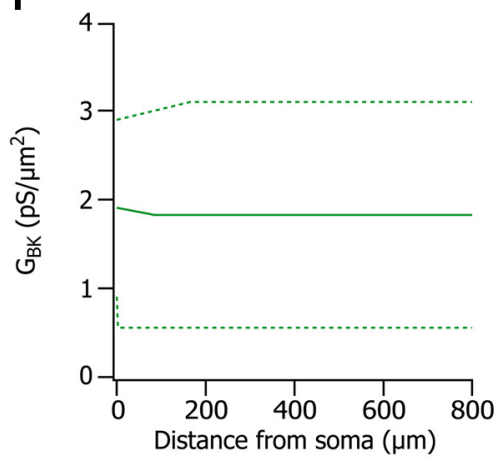

Figure 3. Conductance and permeability gradients in the optimized model. $\boldsymbol{a}$, Passive parameters obtained by the peeling procedure in five experiments. $\boldsymbol{b}$, The average dendritic conductance density of $\mathrm{G}_{\mathrm{Na}}$ (pink line), $\mathrm{G}_{\mathrm{Kf}}$ (blue line), $\mathrm{G}_{\mathrm{Ks}}$ (red line), and $\mathrm{G}_{\mathrm{Ih}}$ (gray line). $c$, The average dendritic permeability density of $\mathrm{P}_{\mathrm{MVA}}$ (solid purple line). The dotted purple lines are the $90 \%$ confidence limits of the average. Inset, The average dendritic permeability density of $\mathrm{P}_{\mathrm{HVA}}$ (solid purple line). The dotted orange lines are the $90 \%$ confidence limits of the average. The dendritic permeability gradient of $\mathrm{Ca}_{\mathrm{MVA}}$ was calculated using the following equation: $P_{\text {MVA }}(x)=P_{\text {MVA,soma }}+P_{\text {MVA,dend }}\left(\exp \left(\left(-\left(x-C a_{\text {MVA,dist }}\right) / C a_{\text {MVA,width }}\right)^{2}\right)\right) \boldsymbol{d}$, The average dendritic permeability density of $P_{H V A}$ (solid orange line). The dotted orange lines are the $90 \%$ confidence limits of the average. $e$, The average dendritic conductance density of $\mathrm{G}_{\mathrm{SK}}$ (solid dark blue line). The dotted dark blue lines are the $90 \%$ confidence limits of the average. $f$, The average dendritic conductance density of $\mathrm{G}_{\mathrm{BK}}$ (solid green line). The dotted green lines are the $90 \%$ confidence

a blocker of $\mathrm{K}_{\mathrm{SK}}$ channels, on the slow after-hyperpolarization of an AP recorded at the soma (Fig. $1 a$, red trace). Figure $1 b$ presents the apamin concentration dependence of the normalized repolarizing velocity of a somatic AP [i.e., the velocity ( $y$-axis) as a function of apamin concentration ( $x$-axis) $]$ with an $\mathrm{IC}_{50}$ of $31 \pm$ $6 \mathrm{nM}(n \geq 4)$.

Next, we tested the effect of blockers for the $K_{B K}$ channel. Figure $1 c-f$ displays the effect of iberiotoxin, and the less specific blocker of voltage-gated $\mathrm{K}^{+}$channels TEA, which in small concentrations mainly blocks BK channels (Storm, 1987; Lang and Ritchie, 1990). Iberiotoxin (Fig. 1c, $30 \mathrm{~nm}$, red trace) and TEA (Fig. $1 d, 1 \mathrm{~mm}$, red trace) had similar effects on the shape of the AP recorded at the soma; namely, the broadening and removal of 
a

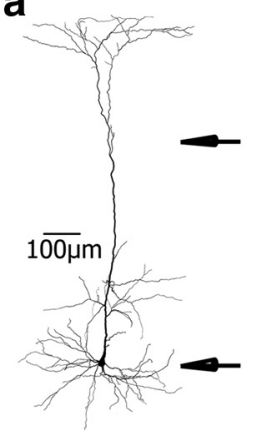

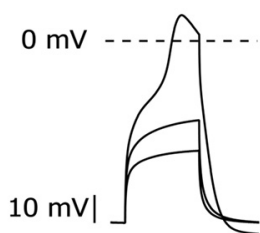
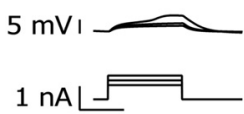
$30 \mathrm{~ms}$
C

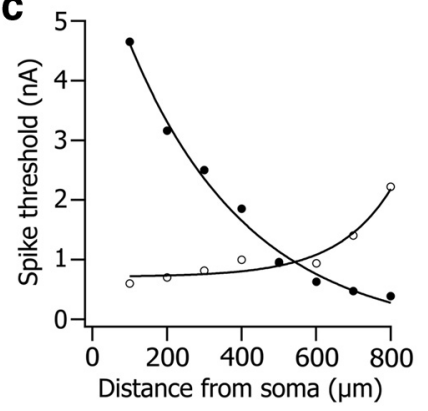

b1

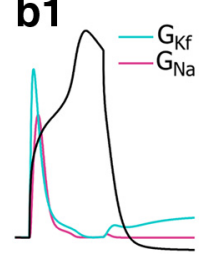

b2

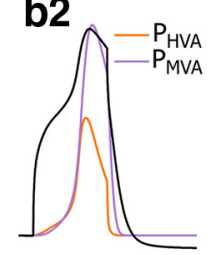

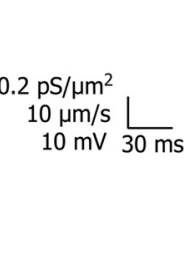

b3

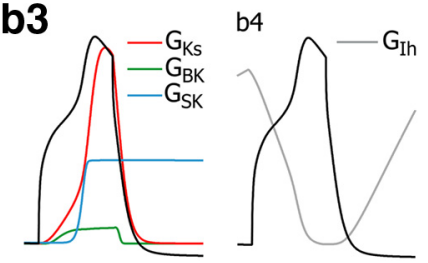

Figure 4. Initiation of a local dendritic regenerative spike. $\boldsymbol{a}$, Reconstruction of an $\mathrm{L} 5$ pyramidal neuron stained with biocytin illustrating electrode placement (left). Right, Simulated somatic and dendritic voltage responses to 50 ms current injection (0.6-1 $\mathrm{nA})$ through the dendritic pipette at $600 \mu \mathrm{m}$, as illustrated on the left. A local dendritic spike was evoked by a $1 \mathrm{nA}$ current. The optimized model used for this simulation was cell 5 (Table 1). $\boldsymbol{b}$, The activation of the eight ion channels inserted into the model during the dendritic regenerative potential (black trace) simulated in $\boldsymbol{a}$. $\boldsymbol{c}$, The simulated threshold for dendritic potential (O) and somatic AP $(O)$ is plotted as a function of the distance from soma. The solid lines are an exponential fit. To obtain a simulated somatic AP, an artificial axon was added to the model; the dendritic $\mathrm{Na}^{+}$conductance density was divided by 10 to simulate the passive forward propagation toward the soma.

the fast afterhyperpolarization. Figure 1e compares the blockade effect of the two blockers on the repolarizing velocity of a somatic AP. We observed no significant difference in the blockade level of these two blockers. Figure if shows the concentration dependence of the blocker TEA as a function of the normalized repolarizing velocity of a somatic $\mathrm{AP}$, with an $\mathrm{IC}_{50}$ of $0.58 \pm 0.04 \mathrm{mM}$ $(n=4)$. Thus, we decided to block the BK channels with a low concentration of TEA instead of using the toxin iberiotoxin.

Based on these pharmacological experiments, the SK channel was blocked with apamin (200 nM), and the BK channel with TEA (1 $\mathrm{mM})$. Simultaneous whole-cell recordings from the soma and along the apical dendrite of L5 pyramidal neurons recorded the membrane potential before and after bath application of this blocker cocktail. Following each recording, the recorded cell was stained, the tissue fixed, and the neuron traced using Neurolucida. The morphology was converted to a code readable by NEURON. This experimental protocol provided an electrophysiological and a morphological dataset for each neuron.

We used this dataset to extend the previous model for L5 pyramidal neurons (Keren et al., 2009). Based on previous work (Foehring et al., 2000; Magistretti et al., 2000; Almog and Korngreen, 2009), we added two types of $\mathrm{Ca}^{2+}$ channel models to this basic model: an $\mathrm{HVA} \mathrm{Ca}^{2+}$ channel and an $\mathrm{MVA} \mathrm{Ca}^{2+}$ channel. We previously pharmacologically identified five possible voltagegated $\mathrm{Ca}^{2+}$ channel types in somatic nucleated patches (Almog and Korngreen, 2009). Thus, the reduction to two channel types in the current model is a simplification that may have to be addressed in future work once more accurate dendritic gradients of these channels are available. Additionally, we inserted two types of $\mathrm{Ca}^{2+}$-gated $\mathrm{K}^{+}$channels models into the model; namely, SK and BK channels (Khaliq et al., 2003; Sun et al., 2003; Akemann and Knöpfel, 2006; Mercer et al., 2007; Deister et al., 2009).

Figure 2 illustrates the application of the numerical peeling procedure to one of the five experimental datasets used here. We

recorded hyperpolarizing and depolarizing membrane potential traces by negative and positive somatic current injections before (Fig. $2 b$, right) and after (Fig. $2 b$, left) blocking $\mathrm{Ca}^{2+}$-gated $\mathrm{K}^{+}$ channels. Next, a genetic algorithm constrained the model in two optimization steps. The average densities of our previously constrained four-conductance model (Keren et al., 2009) were used as an initial estimate for these conductances. We allowed the range of each of the four basic conductances to vary within the 95\% confidence range of our basic model (Keren et al., 2009). The first step optimized a model without $\mathrm{Ca}^{2+}$-activated channels using the dataset recorded in the presence of blockers to these channels (Fig. 2b, left). This first step optimized the density gradients of the MVA and HVA $\mathrm{Ca}^{2+}$ channels (Fig. $2 b$, right). To prevent these optimized parameters from drifting away, the search range for these parameters was then set to $\pm 25 \%$ of the obtained values during the second optimization step in which the full model was optimized using the dataset recorded in standard ACSF ("control conditions"). A linear function described the dendritic conductance gradient for the four new conductances and permeabilities [ $\mathrm{HVA} \mathrm{Ca}^{2+}$ $\left(\mathrm{P}_{\mathrm{HVA}}\right), \mathrm{MVA} \mathrm{Ca}^{2+}\left(\mathrm{P}_{\mathrm{MVA}}\right), \mathrm{SK}\left(\mathrm{G}_{\mathrm{SK}}\right)$, and BK $\left.\left(\mathrm{G}_{\mathrm{BK}}\right)\right]$. This led to a set of parameters describing the passive membrane parameters, the $\mathrm{G}_{\mathrm{Na}}, \mathrm{G}_{\mathrm{Kf}}, \mathrm{G}_{\mathrm{Ks}}, \mathrm{G}_{\mathrm{Ih}}, \mathrm{G}_{\mathrm{SK}}$, and $\mathrm{G}_{\mathrm{BK}}$ dendritic conductance density gradients, and the $\mathrm{P}_{\mathrm{HVA}}$ and $\mathrm{P}_{\mathrm{MVA}}$ dendritic permeability density gradients (Table 1).

We used the somatic current-clamp recordings in the simulations as voltage-clamp commands and trained the genetic algorithm using only the dendritic membrane potential. This procedure provided a good fit for the membrane potential traces recorded with apamin and TEA. It also allowed adequate fitting of the traces recorded without any ion channel blockers (Fig. 2b). To test the reliability of the fit, we clamped the somatic membrane potential of the optimized model to a series of four APs at low and high frequencies. This led to a good reproduction of the measured dendritic data (Fig. $2 c$, dashed blue traces).

Figure 3 shows the parameter sets acquired by applying the peeling procedure to recordings of five cells (see also Table 1). The majority of the passive membrane parameters took on similar values in all five cells (Fig. $3 a$; Table 1), whereas the membrane resistance $\left(\mathrm{R}_{\mathrm{m}}\right)$ showed a large variability. The gradients of the dendritic distributions of $\mathrm{G}_{\mathrm{Ks}} \mathrm{G}_{\mathrm{Kf}}, \mathrm{G}_{\mathrm{Ih}}$, and $\mathrm{G}_{\mathrm{Na}}$ (Fig. 3b; Table 1) were similar to previous experimental reports (Stuart and Sakmann, 1994; Berger et al., 2001; Schaefer et al., 2007; Keren et al., 2009). The mean linear dendritic gradient density of $P_{\mathrm{HVA}}$ and $\mathrm{P}_{\text {MVA }}$ decreased along the apical dendrite (Fig. $3 c, d$ ) and showed the largest variability in the five cells (Table 1). The mean dendritic gradient density of the $\mathrm{G}_{\mathrm{SK}}$ also decreased along the apical dendrite, whereas the mean gradient density of $G_{B K}$ was uniformly distributed over the dendrite.

Parameters can show substantial variability after optimizing a model by a genetic algorithm (Keren et al., 2005; Druckmann et al., 2007, 2008; Gurkiewicz and Korngreen, 2007; Hay et al., 2011). Optimizing the model in several stages using the peeling 
procedure reduces this variability (Keren et al., 2009). We have shown that a CV of the parameter, calculated between models optimized using different datasets, can be used as an indication of the robustness of that parameter (Keren et al., 2009). Here we calculated the CV of five optimized parameter sets (Table 1). The optimized model predicted that the dendritic density of the BK channel would be uniform (Fig. $3 f)$. As a result, the dendritic location at which the linear gradient levels off (Table $1, \mathrm{BK}_{\text {dist }}$ ) was poorly constrained by the genetic algorithm, leading to a high $\mathrm{CV}$ for this parameter. We only included two voltage-gated channels in the model instead of the five that have been pharmacologically identified (Almog and Korngreen, 2009). To partially adjust for this reduction, we allowed the genetic algorithm to shift the activation and inactivation curves of these two pooled $\mathrm{Ca}^{2+}$ channels. The parameters describing the shift to the activation curves of these two channels displayed low CVs, indicating that the model was sensitive to changes in these parameters (Table 1, $\mathrm{Ca}_{\mathrm{MVA} \text {,shift,act }}$ and $\left.\mathrm{Ca}_{\mathrm{HVA} \text {,shift,act }}\right)$. However, the parameters controlling the shift to the inactivation curves (Table $1, \mathrm{Ca}_{\mathrm{MVA}}$, shift,inact and $\left.\mathrm{Ca}_{\mathrm{HVA} \text {,shift,inact }}\right)$ displayed very high CVs. This clearly indicated that the optimization process was insensitive to changes in the inactivation curves of both $\mathrm{Ca}^{2+}$ channels (HVA and MVA) within the search ranges that were defined for the genetic algorithm. Interestingly, the somatic value of the HVA permeability displayed a large $\mathrm{CV}$, possibly indicating that the model of the somatic $\mathrm{Ca}^{2+}$ channels should be expanded (Table 1).

Previous studies have hypothesized that $\mathrm{Ca}^{2+}$ channels may form a highdensity or "hot" $\mathrm{Ca}^{2+}$ zone at the distal dendrite, thus enabling the generation of dendritic $\mathrm{Ca}^{2+}$ spikes (Yuste et al., 1994; Larkum and Zhu, 2002; Schaefer et al., 2003; Larkum et al., 2009; Hay et al., 2011). Nevertheless, our optimized model successfully simulated a $\mathrm{Ca}^{2+}$ spike at the distal dendrite using a linear dendritic gradient density of two $\mathrm{Ca}^{2+}$ channels. To test whether a hot $\mathrm{Ca}^{2+}$ zone at the distal dendrite could also generate a dendritic $\mathrm{Ca}^{2+}$ spike, we optimized the model when a Gaussian-shaped hot zone was added to the spatial profile of the $\mathrm{MVA} \mathrm{Ca}^{2+}$ permeability. Initially, the genetic algorithm freely modified the height, width, and location of the hot zone. This resulted in a hot zone that was not located in one specific place along the apical dendrite. When we constrained the location of the hot zone to the region between 400 and $700 \mu \mathrm{m}$ along the apical dendrite, we obtained a good fit displaying a hot zone with a twofold increase in MVA Ca ${ }^{2+}$ permeability (Fig. $3 c$, insert). Although the genetic algorithm was able to fit the model to the measured dendritic data, it failed to generate a $\mathrm{Ca}^{2+}$ spike at distal locations on the apical dendrite (data not shown).

Next, we tested the ability of the model to predict the physiology of the apical dendrite of L5 pyramidal neurons. We aimed to determine whether the model could predict an ionic mechanism for this activity. Injecting current distally into the apical dendrite of L5 pyramidal neurons can generate a local or "isolated" dendritic spike (Schiller et al., 1997). Thus, we simulated a dendritic spike by injecting $50 \mathrm{~ms}$ current steps into the simulated apical dendrite (using linear gradients of MVA and $\mathrm{HVA} \mathrm{Ca}^{2+}$ permeabilities). Consistent with experimental observations, the optimized model generated a local distal dendritic spike and a 


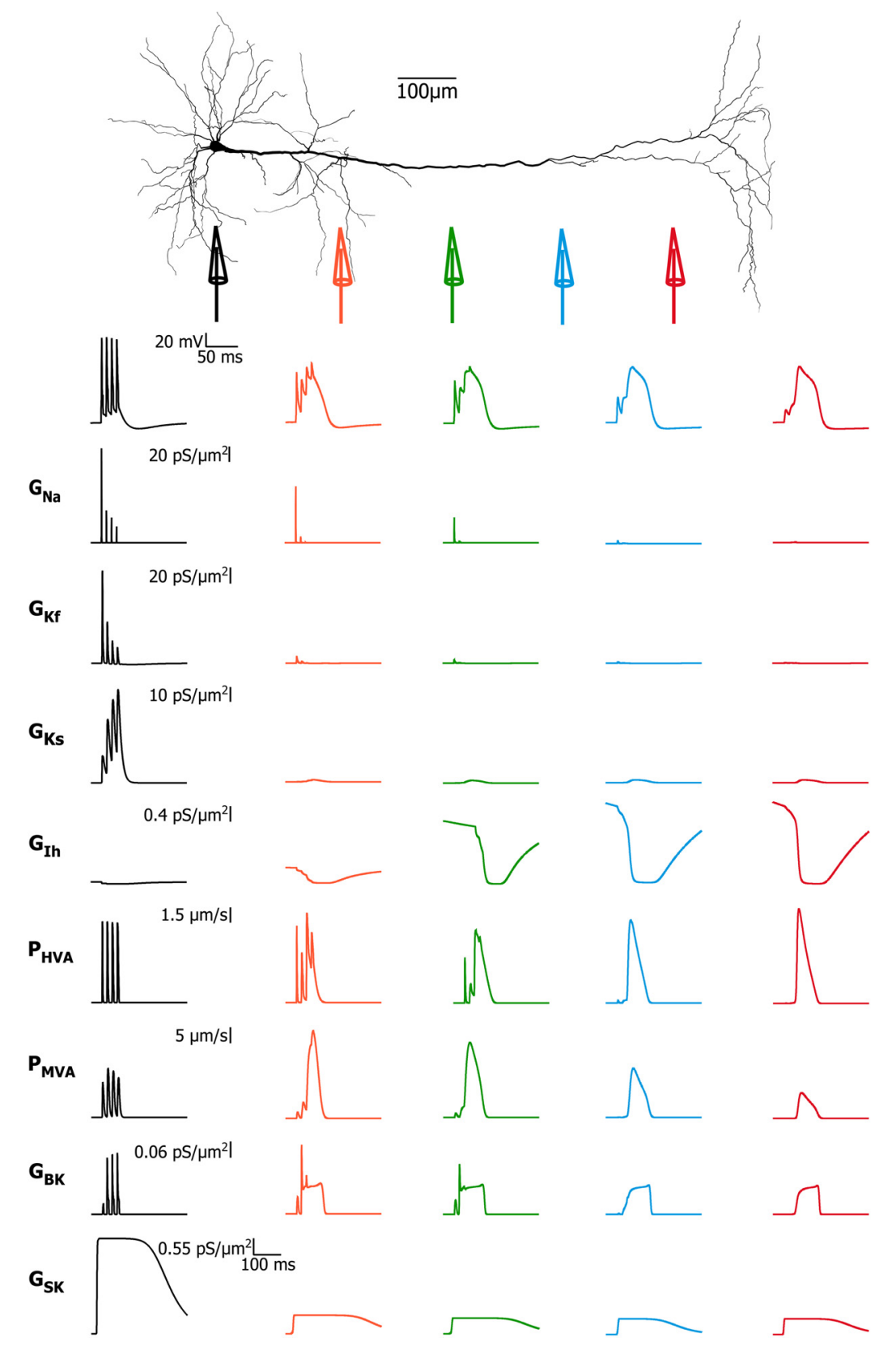

Figure 6. Conductance and permeability activation during a high-frequency series of backpropagating action potentials. In a simulation the somatic membrane potential was clamped to a waveform consisting of a series of four APs with a firing rate of 147 $\mathrm{Hz}$ (black traces) recorded from cell 5 (Table 1). The changes in the membrane potential, the conductance of the six voltage-gated ion channels $\left(\mathrm{Na}, \mathrm{K}_{\mathrm{f}}, \mathrm{K}_{\mathrm{s}}, \mathrm{I}_{\mathrm{h}}, \mathrm{SK}\right.$, and BK), and the permeability of the two voltage-gated $\mathrm{Ca}^{2+}$ channels $\left(\mathrm{CaH}_{\mathrm{VA}}\right.$ and $\left.\mathrm{Ca}_{\mathrm{MVA}}\right)$ included in the model are shown at the soma and at 200, 400,600, and $800 \mu \mathrm{m}$ along the apical dendrite. The traces are color coded according to the simulated pipettes shown on the left.

somatic subthreshold membrane potential deflection (Fig. 4a) predicting a mechanism for the dendritic spike (Fig. $4 b$ ). This mechanism had the following three phases: (1) The $\mathrm{G}_{\mathrm{Na}}$ and $\mathrm{G}_{\mathrm{Kf}}$ conductances were activated and inactivated during stimulus onset (Fig. 4b1), and this initial channel activation boosted the membrane potential, thus bringing it closer to the activation threshold of the voltage-gated $\mathrm{Ca}^{2+}$ channels; (2) the two voltage-gated $\mathrm{Ca}^{2+}$ channels were activated by this initial trigger and continued to depolarize the membrane potential (Fig. 4b2); and (3) the $\mathrm{G}_{\mathrm{Ks}}, \mathrm{G}_{\mathrm{BK}}$, and $\mathrm{G}_{\mathrm{SK}}$ conductances were activated, repolarizing the membrane potential (Fig. $4 b 3$ ). The $I_{\mathrm{h}}$ conductance decreased during the $\mathrm{Ca}^{2+}$ spike (Fig. $4 b 4$ ) and recovered slowly once the membrane potential returned to its resting value. In Figure $4 b 1$, the $\mathrm{G}_{\mathrm{Kf}}$ conductance is activated before the $\mathrm{G}_{\mathrm{Na}}$ conductance as a function of the different activation thresholds of these two channels (the midpoint activation voltage for $\mathrm{K}_{\mathrm{f}}$ conductance was $-47 \mathrm{mV}$, and for the $\mathrm{Na}$ conductance was $-36 \mathrm{mV}$; Keren et al., 2005).

The shallow gradients of the MVA and HVA channels suggested that it should be possible to generate a local dendritic $\mathrm{Ca}^{2+}$ spike both distal and proximal to the soma. However, experimental recordings have only reported spikes distal to the soma (Schiller et al., 1997; Zhu, 2000; Larkum et al., 2001, 2009). To investigate this difference, we generated local spikes at several locations along the apical dendrite of the optimized model (Fig. $4 c$ ). As mentioned above, the optimization was performed only for the apical dendrite, thus eliminating the need to define an AP initiation site at the axon initial segment by applying a somatically recorded membrane potential as a voltage-clamp command during the optimization process. Thus, it was possible to inject current pulses into the apical dendrite without triggering an axonal AP. As predicted by the dendritic gradients, it was possible to generate a spike both proximal and distal to the soma (Fig. $4 c,-$ ). However, the current threshold for generating a local spike increased as the current was injected more proximally to the soma. This result can be easily explained by considering the electrotonic structure of the apical dendrite. Proximal to the soma, the dendrite is thicker than its distal part, and the proximal part also sprouts several oblique dendrites, whereas the distal part is almost bare. Thus, much of the proximally injected current flows to the current sinks generated by oblique dendrites and the soma (Schaefer et al., 2003). Furthermore, the membrane area of the proximal compartment is larger than that of the distal compartment, requiring more current to charge it to the same potential.

To qualitatively investigate the relationship between the threshold of the $\mathrm{Ca}^{2+}$ spike and that of the axonal AP, we attached a model for a cortical axon to the soma (Mainen and Sejnowski, 1996; see also Materials and Methods). This axon was not optimized by the genetic algorithm since we did not have experimental recordings from the axon's initial segment. Injecting a square pulse at various locations along the apical dendrite generated APs at the axon initial segment. As expected, the current threshold of the axonal APs increased as the injection site in the apical dendrite was moved more distally along the dendrite (Fig. $4 c$ ). While qualitative, the intersection between the curves displayed in Figure $4 c$ provided a simple explanation for the appearance of dendritic spikes solely in the 
distal apical dendrite. Current injection into the proximal apical dendrite will passively propagate to the soma and will trigger an AP at the axon initial segment that fails to initiate a dendritic spike due to the electrotonic structure of the proximal dendrite. Conversely, current injection to the distal apical dendrite will attenuate to the soma, failing to generate an AP, but will be large enough to charge the local dendritic membrane to the threshold of the dendritic spike.

It has been shown that a train of lowfrequency AP only backpropagates into the dendrite, whereas a high-frequency train generates a dendritic $\mathrm{Ca}^{2+}$ spike (Larkum et al., 1999b). We tested the ability of our model to predict this physiological observation. We voltage-clamped the soma of the optimized model using an experimentally recorded series of four APs (Fig. 5), and simulated the membrane potential and channel activation along the apical dendrite. At a low AP frequency, the APs backpropagated into the apical dendrite (Fig. 5), in accordance with experimental findings (Stuart and Sakmann, 1994; Larkum et al., 1999b). During backpropagation the $\mathrm{Na}^{+}$channel and the two $\mathrm{Ca}^{2+}$ channels (MVA and HVA) were responsible for dendritic membrane depolarization up to $\sim 400 \mu \mathrm{m}$ from the soma (Fig. 5, orange and green). At more distal locations, backpropagation was almost completely passive. The main channels repolarizing the dendritic membrane potential were the two $\mathrm{Ca}^{2+}$-gated $\mathrm{K}^{+}$ channels (SK and $\mathrm{BK}$ ), whereas the somatic membrane was also repolarized by the two voltage-gated $\mathrm{K}^{+}$channels $\left(\mathrm{G}_{\mathrm{Kf}}\right.$ and $\mathrm{G}_{\mathrm{Ks}} ;$ Fig. 5, black). Figure 6 shows a simulation similar to that in Figure 5 but with a high-frequency somatic AP train. At a high frequency, the optimized model succeeded in generating a dendritic $\mathrm{Ca}^{2+}$ spike beyond $600 \mu \mathrm{m}$ (Fig. 6, blue and red). At this frequency, the $\mathrm{Na}^{+}$channel contributed mainly to the first spike along the dendrite (Fig. 6). The main channels repolarizing the dendritic membrane were the two $\mathrm{Ca}^{2+}$-gated $\mathrm{K}^{+}$channels $\left(\mathrm{G}_{\mathrm{SK}}\right.$ and $\mathrm{G}_{\mathrm{BK}}$; Fig. 6). The somatic membrane was also repolarized by the two voltage-gated $\mathrm{K}^{+}$channels $\left(\mathrm{G}_{\mathrm{Kf}}\right.$ and $\mathrm{G}_{\mathrm{Ks}}$; Figs. 5, 6, black). The MVA Ca ${ }^{2+}$ channel contributed more than the HVA $\mathrm{Ca}^{2+}$ channel during the dendritic $\mathrm{Ca}^{2+}$ spike (Fig. 6), as pointed out in Figure $4 b$. The optimized model faithfully predicted experimental patterns of intracellular $\mathrm{Ca}^{2+}$ concentration (Larkum et al., 1999b). Following a low-frequency train of backpropagating APs, the intracellular $\mathrm{Ca}^{2+}$ concentration increased at the soma and the proximal apical dendrite (Fig. 7, left). However, following a high-frequency train of APs the intracellular $\mathrm{Ca}^{2+}$ concentrations increased from the soma all the way to the distal apical dendrite (Fig. 7, right).

It has been shown that temporal coupling of a backpropagated $\mathrm{AP}$ with synaptic inputs generates a backpropagation-activated $\mathrm{Ca}^{2+}$ spike (BAC) firing (Larkum et al., 1999a,b, 2001). To test whether our model can predict BAC firing, we again added an arti-

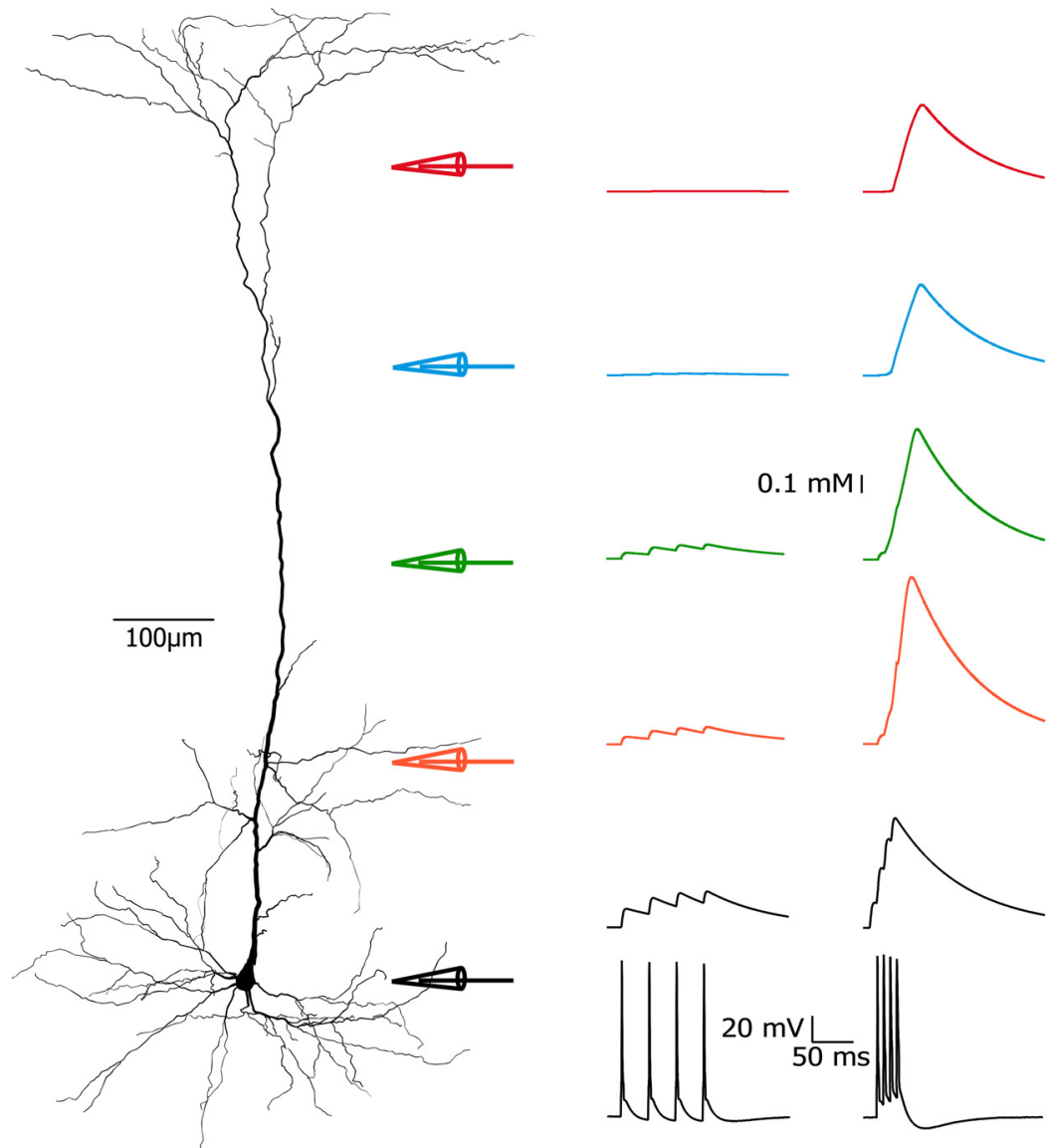

Figure 7. Intracellular $\mathrm{Ca}^{2+}$ concentration during low- and high-frequency stimulation. In a simulation, the somatic membrane potential was clamped to a waveform comprising a series of four APs with a firing rate of $39 \mathrm{~Hz}$ (left) and $147 \mathrm{~Hz}$ (right) (black (taces) recorded from cell 5 (Table 1). The parameter $\mathrm{Ca}_{\mathrm{i}}$ in the optimized model was used to track the intracellular $\mathrm{Ca}^{2+}$ concenintracellular $\mathrm{Ca}^{2+}$ concentration are millimolar due to the absence of a $\mathrm{Ca}^{2+}$ buffer in the model. The traces are color coded according to the simulated pipettes shown on the left.

ficial axon to the cell body (Mainen and Sejnowski, 1996). Then we injected a subthreshold EPSP-like current of $1.6 \mathrm{nA}$ into the distal apical dendrite (at $800 \mu \mathrm{m}$; Fig. $8 b$, gray). This potential attenuated along the dendrite (Fig. $8 b$, red and blue) toward the soma (Fig. $8 b$, black). A somatic current injection of $0.5 \mathrm{nA}$ generated a somatic AP that backpropagated into the apical dendrite (Fig. $8 \mathrm{c}$ ). Coupling the subthreshold EPSP-like current (Fig. $8 b$, gray) and the somatic current (Fig. $8 b$, black) with a time window of $5 \mathrm{~ms}$ caused the optimized model to generate a BAC firing (Fig. $8 d$, red), followed by two additional somatic APs (Fig. 8d, black). Injecting a higher EPSP-like current ( $3 \mathrm{nA})$ into the distal apical dendrite also generated a $\mathrm{Ca}^{2+}$ spike and somatic APs (Fig. $8 e$ ). BAC firing is highly dependent on the timing of the backpropagating AP and dendritic synaptic input (Larkum et al., 1999a, their Fig. 2). Our model was able to predict this temporal dependency. Figure 9 displays the temporal coupling of a backpropagated $\mathrm{AP}$ with the synaptic inputs required to simulate $\mathrm{BAC}$ firing. The time interval for a BAC firing was up to $7 \mathrm{~ms}$ (Fig. 9b). When the delay between the AP and the EPSP was changed to -10 or $10 \mathrm{~ms}$, the optimized model did not generate BAC firing (Fig. 9a,c).

In our optimized model, the distal EPSP and the backpropagating AP collided at $\sim 470 \mu \mathrm{m}$ from the soma. Thus, we exam- 
a

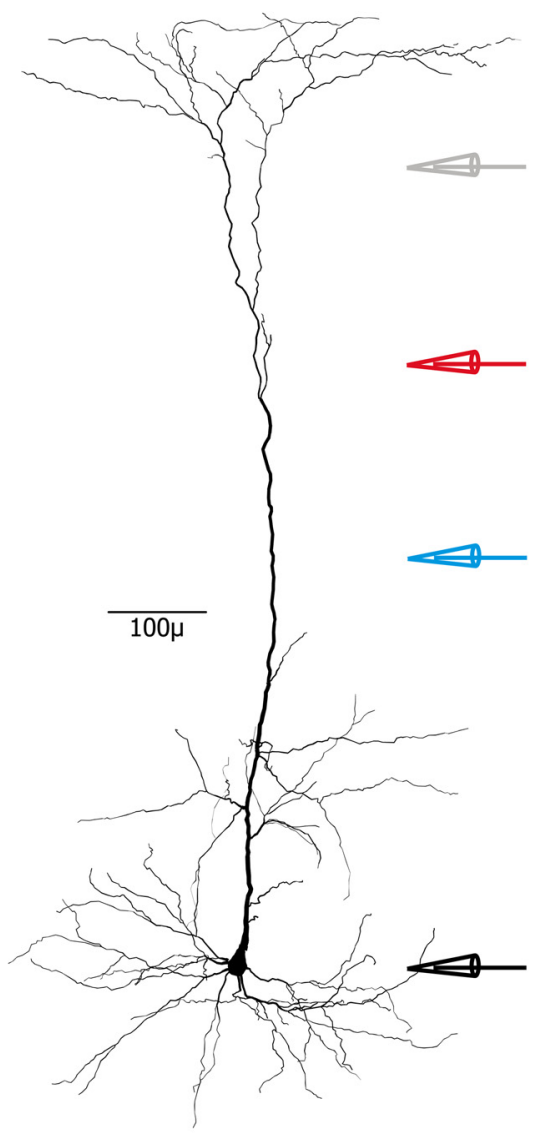

b

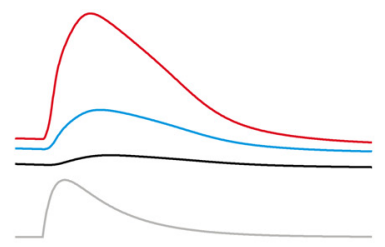

C

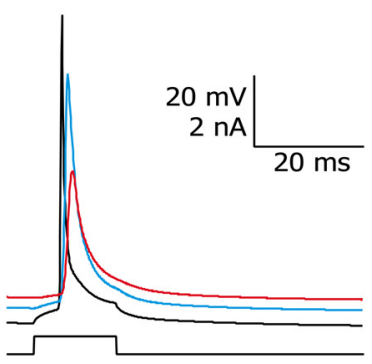

d

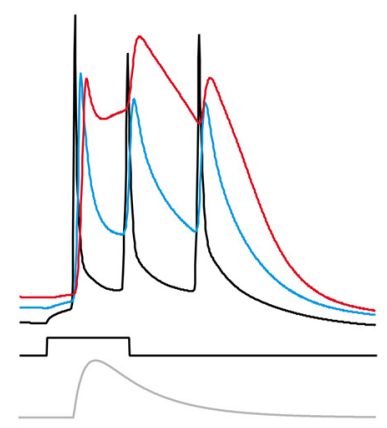

e

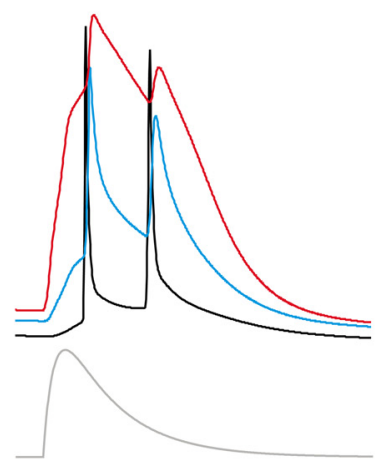

Figure 8. Reproducing BAC firing. $\boldsymbol{a}$, Reconstruction of an $L 5$ pyramidal neuron stained with biocytin, illustrating electrode placement. $\boldsymbol{b}$, EPSP-like current of $1.6 \mathrm{nA}$ (rising $\tau=2 \mathrm{~ms}$, declining $\tau=10 \mathrm{~ms}$ ) was injected through the gray pipette ( $800 \mu \mathrm{m}$, bottom) into a dendrite of one of the optimized models (Table 1, cell 5). The simulated voltage response showed the shape of an EPSP at the soma (black trace) and at the apical dendrite (400 $\mu \mathrm{m}$, blue trace; $600 \mu \mathrm{m}$, red trace). c, Injection of a square current of $0.5 \mathrm{nA}$ through the somatic pipette (black, bottom). The action potential generated at the soma backpropagated along the apical dendrite. $\boldsymbol{d}$, The combination of the two stimuli used in $\boldsymbol{b}$ and $\boldsymbol{c}$ with a time interval of $5 \mathrm{~ms}$ generated a BAC firing at the distal apical dendrite (red trace). $e$, EPSP-like current injection of $3 \mathrm{nA}$ (rising $\tau=2 \mathrm{~ms}$, declining $\tau=10 \mathrm{~ms}$ ) through the gray pipette (800 $\mu \mathrm{m}$, bottom) was sufficient to generated a $\mathrm{Ca}^{2+}$ spike at the distal apical dendrite (red trace).

ined the mechanism at $470 \mu \mathrm{m}$ along the apical dendrite where the two stimuli converged, and at $600 \mu \mathrm{m}$ from the soma, where the dendritic spike was fully developed (Fig. 8d, red). At $600 \mu \mathrm{m}$ during the BAC firing (Fig. 10b), the multistep mechanism was similar to that observed for a dendritic spike, as shown in Figures 4 and 6 . First, the $\mathrm{G}_{\mathrm{Na}}$ and $\mathrm{G}_{\mathrm{Kf}}$ conductances were activated and were basically responsible for the first $\mathrm{Na}^{+}$spike (Fig. 10c, left). Unlike Figure 4, the $\mathrm{G}_{\mathrm{Na}}$ conductance was activated before the $\mathrm{G}_{\mathrm{Kf}}$ conductance, since a Na${ }^{+}$spike first propagated from the soma and was not generated locally. Next, the two $\mathrm{Ca}^{2+}$ channels, but mainly the $\mathrm{P}_{\mathrm{MVA}}$, were activated and were responsible for the continued depolarization (Fig. 10b, middle). The three $\mathrm{K}^{+}$conductances $\left(\mathrm{G}_{\mathrm{Ks}}, \mathrm{G}_{\mathrm{BK}}\right.$, and $\left.\mathrm{G}_{\mathrm{SK}}\right)$, but mainly the $\mathrm{G}_{\mathrm{Ks}}$ conductance, repolarized the dendritic membrane (Fig. 10b, right). The mech- anism at $470 \mu \mathrm{m}$ was similar, except that the $\mathrm{P}_{\text {MVA }}$ permeability had less impact on the membrane depolarization (Fig. 10c, middle) and the $\mathrm{G}_{\mathrm{Ks}}$ conductance also had less influence on membrane repolarization (Fig. 10c, right). These differences fit the absence of a $\mathrm{Ca}^{2+}$ spike at $470 \mu \mathrm{m}$. Here there were only backpropagating APs (Fig. 10c, black).

Strong dendritic spikes are known to induce AP firing at the axon initial segment (Larkum et al., 1999a,b, 2001). The model was able to faithfully predict this effect, which was simulated by injecting a large EPSP-like current into the distal apical dendrite (Fig. $8 e$, red). Since the $\mathrm{Ca}^{2+}$ spike generated at the distal dendrite lacked the backpropagating $\mathrm{Na}^{+}$spike, it forward propagated toward the soma. The mechanism was essentially the same as that in Figures 4, 5, 6, and 8. First, the $\mathrm{G}_{\mathrm{Na}}$ and the $\mathrm{G}_{\mathrm{Kf}}$ conductances contributed to the changes in the membrane potential (Fig. $11 b, c$, left), but at the distal dendrite $(600 \mu \mathrm{m})$ these conductances did not participate in the $\mathrm{Na}^{+}$spike, as mentioned above (Fig. 11b, left). In contrast, at the more proximal dendrite $(470 \mu \mathrm{m})$ these conductances partially contributed to the first spike (Fig. 11c, left). Next, the two $\mathrm{Ca}^{2+}$ permeabilities continued to depolarize the dendritic membrane at both locations (Fig. 11b,c, middle); these two permeabilities had a greater impact on the membrane depolarization at the distal dendrite $(600 \mu \mathrm{m})$, where the $\mathrm{Ca}^{2+}$ spike occurred (Fig. 11b, middle). Then, the dendritic membrane repolarized as a result of the slow activation of the $G_{K s}, G_{B K}$, and $\mathrm{G}_{\mathrm{SK}}$ conductances (Fig. $11 b, c$, right), but the $\mathrm{G}_{\mathrm{Ks}}$ conductance had a greater effect on the repolarization at $600 \mu \mathrm{m}$ (Fig. $11 b$, right).

The proximal apical dendrite modulates the coupling between the axonal AP initiation zone and the $\mathrm{Ca}^{2+}$ spike initiation zone in the distal apical dendrite (Larkum et al., 2001). Depolarization of the proximal apical dendrite increases coupling, whereas hyperpolarization decreases it (Larkum et al., 2001). To test the ability of our model to predict this modulation, we injected current into the proximal apical dendrite of our optimized model to test whether this zone could affect the propagation of a distal dendritic spike. We injected an EPSP-like current of $2 \mathrm{nA}$ into the distal apical dendrite (at $800 \mu \mathrm{m}$; Fig. $12 b 1$, gray). The dendritic potential simulated at the distal apical dendrite (Fig. 12b1, red) failed to propagate toward the soma (Fig. 12b1, blue and black). A small depolarization (0.2 nA, $50 \mathrm{ms,}$ onset $30 \mathrm{~ms}$ before the EPSP-like waveform) at the proximal apical dendrite (at $300 \mu \mathrm{m}$; Fig. 12b2, blue pipette) was able to simulate a $\mathrm{Ca}^{2+}$ spike at the distal dendrite (Fig. 12b2, red), followed by two somatic APs (Fig. 12b2, black). Alternatively, a somatic AP elicited after injection of an EPSP-like waveform at 
the distal dendrite (at $800 \mu \mathrm{m}$; Fig. 12c1, gray and black) could be blocked (Fig. $12 c 2$, black) by the injection of a hyperpolarized current $(-0.4 \mathrm{nA}, 50 \mathrm{~ms}$, onset 30 $\mathrm{ms}$ before the EPSP-like waveform; Fig. $12 c 2$, blue) at the proximal dendrite.

Previous studies have shown that within a compartment, the neuronal inputs are summed nonlinearly, whereas the output of different compartments sums linearly (Polsky et al., 2004; Larkum et al., 2009). We used the optimized model to simulate NMDA spikes at thin dendrite branches and to examine the information integration. We inserted NMDA and AMPA synapses (Larkum et al., 2009) in the model within the same dendritic branch (the distance between the pipettes was $26 \mu \mathrm{m}$; Fig. 13b, left) and between two branches (Fig. 13b, right). First, we activated the synapses separately and then simultaneously (Fig. 13b). Figure 13c compares the EPSP integral of the combined stimulus (Fig. 13b, red) with the expected EPSP integral (summation of the two individual stimuli; Fig. 13b, blue). The input integration within the same branch was linear for a weak stimulus and became nonlinear as the stimulus intensity increased (Fig. 13b, left, $c$, red). By contrast, the summation of the inputs between branches remained linear regardless of the stimulus intensity (Fig. 13b, right, $c$, blue).

\section{Discussion}

We applied an adaptation of the Hodgkin-Huxley methodology to derive a mechanistic model for the apical dendrite of neocortical L5 pyramidal neurons. Using experimentally known channel kinetics, a pharmacological peeling procedure (Figs. 1, 2), and a genetic optimization algorithm, we were able to reduce the parameter space to manageable segments. The model predicted an ionic mechanism for the generation of dendritic spike (Figs. $3,4,5)$, the interaction of this spike with the backpropagating AP (Figs. 4, 8, 9), the ability of the proximal apical dendrite to control the coupling between the axon and the dendrite (Fig. 12), and the generation of NMDA spikes in the distal apical tuft (Fig. 13).

Our approach allowed us to constrain a mechanistic model for L5 pyramidal neurons containing passive parameters, and eight ion conductances and permeabilities known to be expressed in the membrane of this neuron (Stuart and Sakmann, 1994; Berger et al., 2001; Larkum et al., 2001; Benhassine and Berger, 2005; Schaefer et al., 2007; Almog and
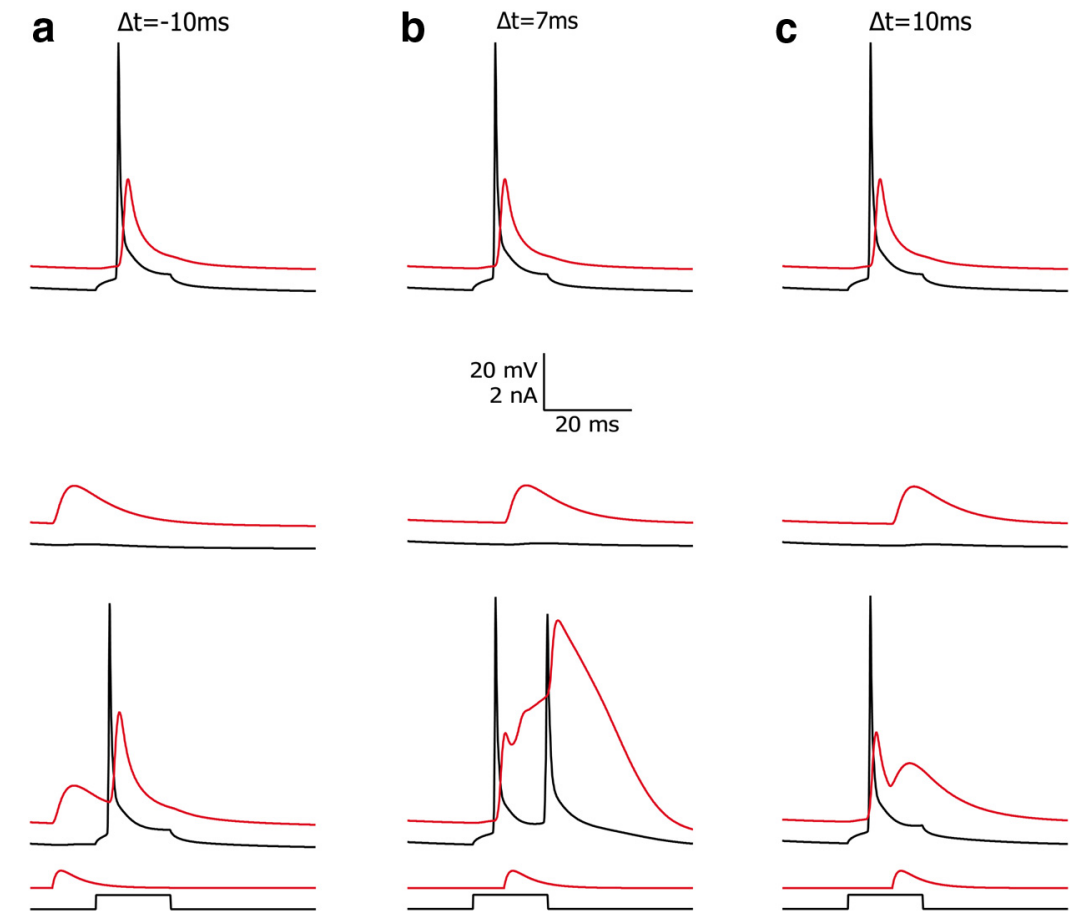

Figure 9. The timing of BAC firing. Top, EPSP-like current of $0.6 \mathrm{nA}$ (rising $\tau=1 \mathrm{~ms}$, declining $\tau=5 \mathrm{~ms}$ ) was injected at the distal dendrite $(800 \mu \mathrm{m})$ into a dendrite of one of the optimized models (Table 1, cell 5). The simulated voltage response showed the shape of an EPSP at the soma (black trace) and at the apical dendrite (600 $\mu \mathrm{m}$, red trace). Middle, Injection of a square current of $0.5 \mathrm{nA}$ through the somatic pipette (black, bottom). The action potential generated at the soma backpropagated along the apical dendrite. Bottom, Combining the two stimuli used with a different time interval ( $\boldsymbol{a},-10 \mathrm{~ms} ; \boldsymbol{b}, 7 \mathrm{~ms} ; \boldsymbol{c}, 10 \mathrm{~ms}) . \mathrm{A} \mathrm{Ca}^{2+}$ spike was simulated using a time interval of $7 \mathrm{~ms}$. $\Delta t$ was calculated as the time between the start of the somatic injection and the start of the dendritic injection.

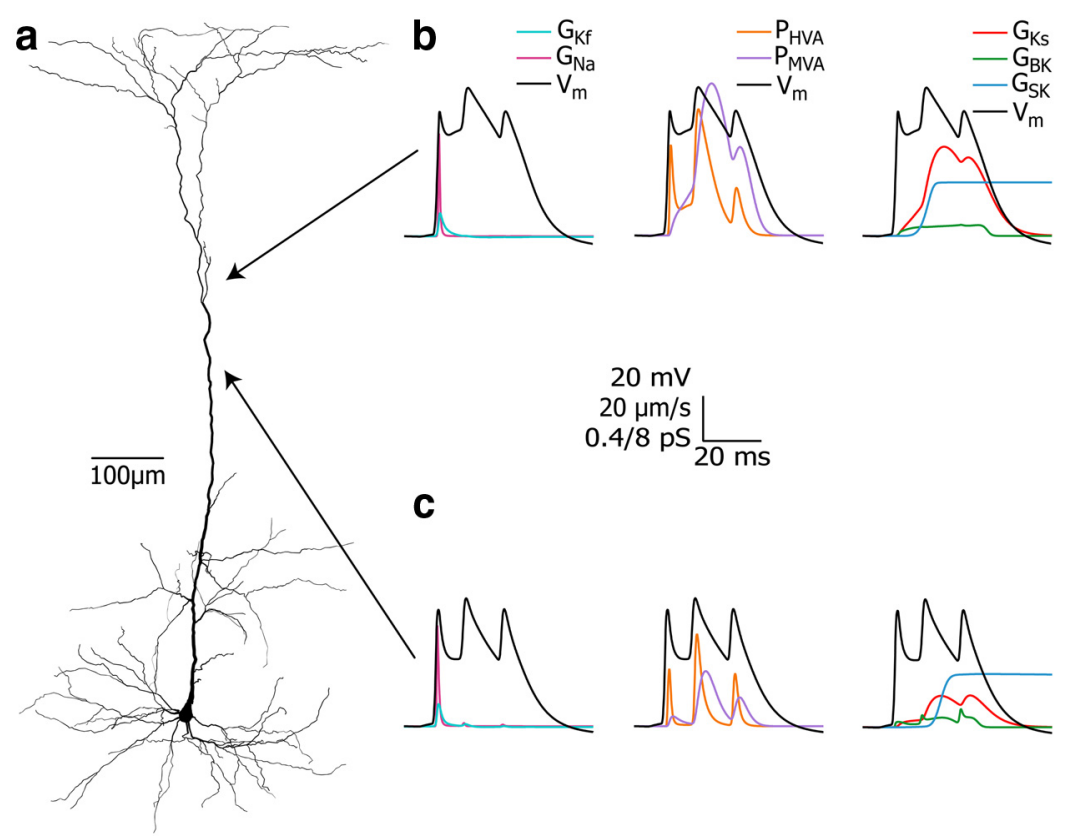

Figure 10. Conductance and permeability activation during BAC firing. $\boldsymbol{a}$, Reconstruction of an $L 5$ pyramidal neuron stained with biocytin illustrating electrode placement. $\boldsymbol{b}$, The activation of seven ion channels inserted into the model during the BAC firing simulated in Figure $5 d$ at $600 \mu \mathrm{m}$ from the soma. Left, Activation of $\mathrm{G}_{\mathrm{Na}}$ (pink trace) and $\mathrm{G}_{\mathrm{Kf}}$ (blue trace) conductances. Middle, Activation of $\mathrm{P}_{\mathrm{HVA}}$ (orange trace) and $\mathrm{P}_{\mathrm{MVA}}$ (purple trace) permeabilities. Right, Activation of $\mathrm{G}_{\mathrm{Ks}}$ (red trace), $\mathrm{G}_{\mathrm{BK}}$ (green trace), and $\mathrm{G}_{\mathrm{SK}}$ (dark blue trace) conductances. $c$, The activation of seven ion channels inserted into the model during the BAC firing simulated in Figure $5 d$ at $470 \mu \mathrm{m}$ from the soma. Left, Activation of $G_{N a}$ (pink trace) and $G_{K f}$ (blue trace) conductances. Middle, Activation of $\mathrm{P}_{\mathrm{HVA}}$ (orange trace) and $\mathrm{P}_{\mathrm{MVA}}$ (purple trace) permeabilities. Right, Activation of $\mathrm{G}_{\mathrm{KS}}$ (red trace), $\mathrm{G}_{\mathrm{BK}}$ (green trace), and $\mathrm{G}_{\mathrm{SK}}$ (dark blue trace) conductances. 


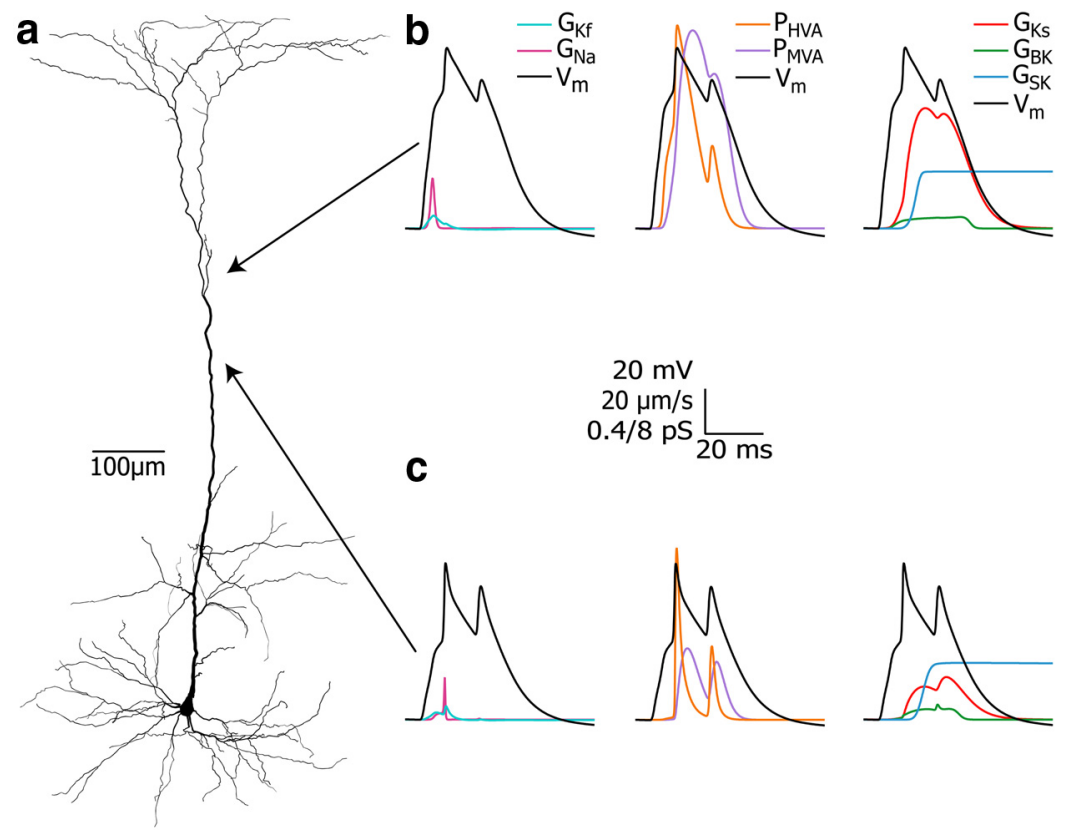

Figure 11. Conductance and permeability activation during a complex $\mathrm{Ca}^{2+}$ spike. $\boldsymbol{a}$, Reconstruction of a filled $\mathrm{L} 5$ pyramidal neuron stained with biocytin, illustrating electrode placement. $\boldsymbol{b}$, The activation of seven ion channels inserted into the model during the dendritic $\mathrm{Ca}^{2+}$ spike simulated in Figure $5 e$ at $600 \mu \mathrm{m}$ from the soma. Left, Activation of $\mathrm{G}_{\mathrm{Na}}$ (pink trace) and $\mathrm{G}_{\mathrm{Kf}}$ (blue trace) conductances. Middle, Activation of $\mathrm{P}_{\mathrm{HVA}}$ (orange trace) and $\mathrm{P}_{\mathrm{MVA}}$ (purple trace) permeabilities. Right, Activation of $\mathrm{G}_{\mathrm{KS}}$ (red trace), $G_{B K}$ (green trace), and $G_{S K}$ (dark blue trace) conductances. $c$, The activation of seven ion channels inserted into the model during the dendritic $\mathrm{Ca}^{2+}$ spike simulated in Figure $5 e$ at $470 \mu \mathrm{m}$ from the soma. Left, Activation of $\mathrm{G}_{\mathrm{Na}}$ (pink trace) and $\mathrm{G}_{\mathrm{Kf}}$ (blue trace) conductances. Middle, Activation of $\mathrm{P}_{\mathrm{HVA}}$ (orange trace) and $\mathrm{P}_{\mathrm{MVA}}$ (purple trace) permeabilities. Right, Activation of $\mathrm{G}_{\mathrm{KS}}$ (red trace), $G_{B K}$ (green trace), and $G_{S K}$ (dark blue trace) conductances.

Korngreen, 2009; Deister et al., 2009). The passive parameters and the gradient of the dendritic distribution of fast and slow voltage-gated $\mathrm{K}^{+}$channels $\left(\mathrm{K}_{\mathrm{f}}\right.$ and $\mathrm{K}_{\mathrm{s}}$ ), the voltage-gated $\mathrm{Na}^{+}$ channel and the $I_{\mathrm{h}}$ evolved to resemble previous experimental reports (Stuart and Sakmann, 1994; Berger et al., 2001; Larkum et al., 2001; Schaefer et al., 2007; Keren et al., 2009). Additionally, the mean dendritic density gradient of the $\mathrm{G}_{\mathrm{SK}}$ decreased along the apical dendrite. The $\mathrm{G}_{\mathrm{BK}}$ showed a uniform distribution, as was also found along the somatodendritic axis in the few previous studies of this channel (Benhassine and Berger, 2005). Both $\mathrm{Ca}^{2+}$ channels (HVA and MVA) showed a mean dendritic density gradient that decreased linearly along the apical dendrite (Fig. 3). These ion gradients along the somatodendritic axis in the model successfully simulated many dendritic electrophysiological events observed experimentally in L5 pyramidal neurons: AP backpropagation (Stuart and Sakmann, 1994; Stuart et al., 1997); regenerative dendritic $\mathrm{Na}^{+}$and $\mathrm{Ca}^{2+}$ spikes (Schiller et al., 1997; Larkum et al., 1999a,b); BAC firing (Larkum et al., 1999a,b, 2001); changes in intracellular $\mathrm{Ca}^{2+}$ concentration (Schiller et al., 1995; Larkum et al., 1999b; Larkum and Zhu, 2002); and synaptic integration (Polsky et al., 2004; Larkum et al., 2009).

The optimized model predicted a mechanism of regenerative dendritic spikes (Fig. 4), and showed that a regenerative dendritic spike arises through a multistep mechanism, as follows: (1) $\mathrm{Na}^{+}$and $\mathrm{K}_{\mathrm{f}}$ channels contribute to the $\mathrm{Na}^{+}$spike generated during spike onset, and due to the different kinetics of the channels, the $\mathrm{K}_{\mathrm{f}}$ channel is activated before the $\mathrm{Na}^{+}$ channel for subthreshold events and vice versa for suprathreshold events; (2) the two $\mathrm{Ca}^{2+}$ channels, mainly $\mathrm{MVA} \mathrm{Ca}^{2+}$ channels, contribute to the continuing depolarization; and (3) the remaining $\mathrm{K}^{+}$channels (voltage- and $\mathrm{Ca}^{2+}$-gated) are responsible for membrane repolarization.
The optimized model predicted that the mechanism for the generation of dendritic spikes would be expressed throughout the apical dendrite in an almost uniform manner. The density of most voltage-gated channels included in the model leveled to a constant value approximately half way along the apical dendrite, with some channels leveling off even proximal to the soma (Fig. 3). This suggested that it should be possible to initiate a dendritic spike in any location along the apical dendrite. This appeared at first to contradict experimental observations showing that a dendritic spike could only be triggered in the distal apical dendrite (Amitai et al., 1993; Schiller et al., 1997; Larkum et al., 1999a, 2001; Pérez-Garci et al., 2013). This can be accounted for by considering the threshold for spike initiation in the axon initial segment (Fig. 4c). Specifically, the proximal dendritic current injection passively propagates to the axon initial segment and generates an AP before the local dendritic depolarization crosses the threshold for the generation of a dendritic spike. Furthermore, the increase in the threshold of the dendritic spike proximal to the soma, probably due to the passive properties of the proximal apical dendrite, provides a computational model for the ability of this region to control the coupling between the distal dendrite and the axon. Depolarization of the proximal dendrite allows the forward-propagating dendritic spike to cross the local threshold for dendritic spike generation, thus facilitating active forward propagation of this spike in the direction of the soma (compare Fig. 12 with Larkum et al., 2001). It is important to note that the interactions of the dendritic spike with the axonally generated AP have been investigated by attaching an artificial axon to the optimized soma (Mainen and Sejnowski, 1996). This artificial axon was used since we did not have experimental recordings from the axon that could be used to optimize a model for that cellular section (Keren et al., 2005). Thus, the results presented in Figures $4 c$, 8,9 , and 12 should be considered as qualitative alone. Nevertheless, these simulations provide computational predictions regarding the mechanism controlling the interaction between dendritic and axonal spikes.

Our current model predicts a different mechanism for the initiation of dendritic spikes from those previously suggested by other numerical simulations (Schaefer et al., 2003; Larkum et al., 2009; Hay et al., 2011). Previous models of dendritic spiking in L5 pyramidal neurons assumed the existence of a dendritic hot zone of low-threshold activated ( $t$-type), voltage-gated $\mathrm{Ca}^{2+}$ channels in the distal apical dendrite (Schaefer et al., 2003; Larkum et al., 2009; Hay et al., 2011). These are the two major differences between our model and these previous studies. Our model does not contain a $t$-type $\mathrm{Ca}^{2+}$ channel because we did not observe this type of current in our somatic nucleated patch recordings (Almog and Korngreen, 2009). Our model includes an MVA channel whose kinetics were largely based on these recordings. This was the primary reason for our lack of success in optimizing a working model when we assumed that a hot zone of MVA chan- 
nels existed in the distal apical dendrite (Fig. 3). MVA channels require a larger depolarization than the $t$-type channels to participate in a regenerative dendritic event. Thus, a hot zone of these channels was not hot enough to generate a $\mathrm{Ca}^{2+}$ spike.

We have previously suggested an optimization scheme for a full compartmental model of a neuron using multiple voltage recordings from the soma, axon, and dendrite as a training dataset for the genetic algorithm (Keren et al., 2005). We have also shown that the point-by-point sum of squares is sufficient as a cost function to constrain a model for a single dendrite, as long as the somatic membrane potential is used as a voltage-clamp command and a parameter peeling procedure is applied (Keren et al., 2009). An intriguing alternative to the peeling procedure requires the sampling of the membrane potential from many locations along the soma, dendrites, and axon (Huys et al., 2006). Unfortunately, such massive parallel recordings of the membrane potential requires considerably better voltage-sensitive dyes than we have at present. The results presented here suggest that finding large parameter manifolds is partly due to optimizing the model by only using the averages of extracted AP and dendritic spike features as training datasets (Hay et al., 2011). It is clear that to optimize a model for a cellular region displaying regenerative activity, it is imperative to obtain membrane potential recordings from that region. Even with this expanded dataset, pharmacological parameter peeling and multistage optimization are required to avoid local minima.

The contradiction between our linear model and the previously suggested hot zone model cannot be resolved computationally. Hot zone models have predicted many physiological properties of L5 pyramidal neurons (Schaefer et al., 2003; Larkum et al., 2009; Hay et al., 2011). The best way to resolve this issue would be to experimentally determine, probably using the patch-clamp technique, the dendritic density gradient of voltage-gated $\mathrm{Ca}^{2+}$ channels. This experimental verification of our simulation will also serve to further expand the current model that only contains two voltage-gated $\mathrm{Ca}^{2+}$ channels. Sadly, although several valiant but fruitless attempts have been made, these dendritic $\mathrm{Ca}^{2+}$ gradients have yet to be determined.

The simulations illustrated in Figure $4 c$ suggest an experiment that may be used to support the model we presented. The simulations predict that it would be possible to trigger a dendritic spike even in the proximal apical dendrite following a complete block of the voltage-gated $\mathrm{Na}^{+}$channels in the axon initial seg-

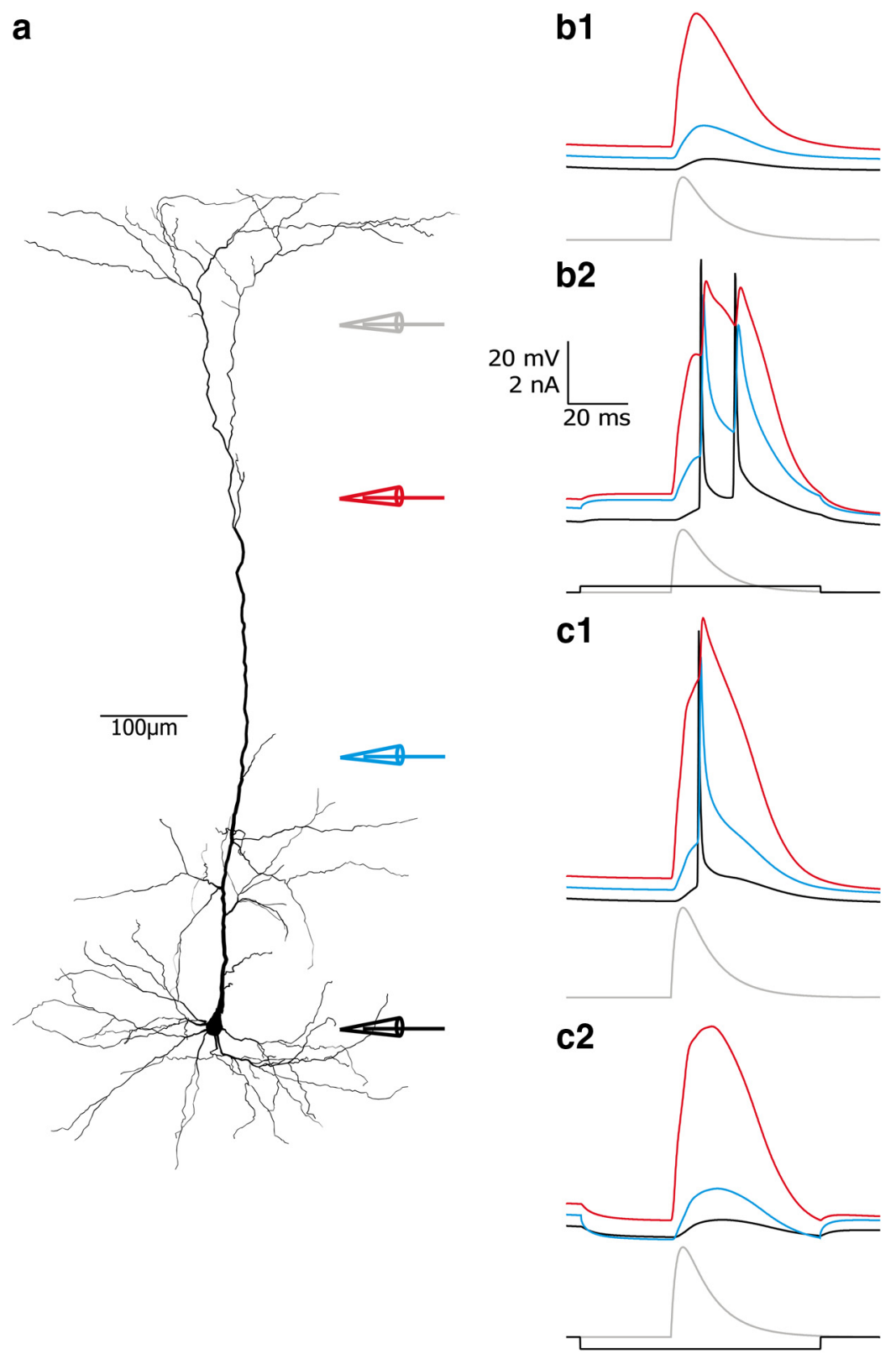

Figure 12. Modulation of the dendritic spike propagation. $\boldsymbol{a}$, Reconstruction of a filled $L 5$ pyramidal neuron stained with biocytin, illustrating electrode placement. $\boldsymbol{b}$, A dendritic spike changed to BAC firing. $\boldsymbol{b} 1$, An EPSP-like current of $2 \mathrm{nA}$ (rising $\tau=$ $2 \mathrm{~ms}$, declining $\tau=10 \mathrm{~ms}$ ) was injected through the gray pipette $(800 \mu \mathrm{m})$ into a dendrite of one of the optimized models (Table 1, cell 5). The simulated voltage response showed the shape of an EPSP at the soma (black trace) and at the apical dendrite (300 $\mu \mathrm{m}$, blue trace; $600 \mu \mathrm{m}$, red trace). $\mathbf{b 2}$, A small depolarizing current at the proximal dendrite (300 $\mu \mathrm{m}$, blue electrode) was injected $\left(0.2 \mathrm{nA}, 50 \mathrm{~ms}\right.$, onset $30 \mathrm{~ms}$ before the EPSP-like current). The dendritic spike converted to a $\mathrm{Ca}^{2+}$ spike at the distal dendrite (red trace). $c$, A dendritic AP changed to a dendritic spike. c1, An EPSP-like current injection of $3 \mathrm{nA}$ (rising $\tau=2 \mathrm{~ms}$, declining $\tau=10 \mathrm{~ms}$ ) through the gray pipette $(800 \mu \mathrm{m}$, bottom) generated a dendritic potential at the distal apical dendrite (red trace) that propagated to the soma (black trace). $\mathbf{2}$, Hyperpolarizing current ( $-0.4 \mathrm{nA}, 50 \mathrm{~ms}$, onset $30 \mathrm{~ms}$ before the EPSP-like current) was injected into the proximal dendrite ( $300 \mu \mathrm{m}$, blue electrode). The hyperpolarizing current caused the dendritic AP to convert to a dendritic spike (red trace).

ment. Thus, a possible experiment would entail a simultaneous recording from the soma and various distances along the apical dendrite and an application electrode puffing tetrodotoxin at the axon initial segment. Should such an experiment reproduce the predicted spike threshold profile (Fig. 4c), it would strengthen the predictions of our model. Finally, applying the peeling procedure to quantitative modeling of the axon initial segment would doubtless lead to a more comprehensive modeling of L5 pyramidal neurons and other cortical axons. 


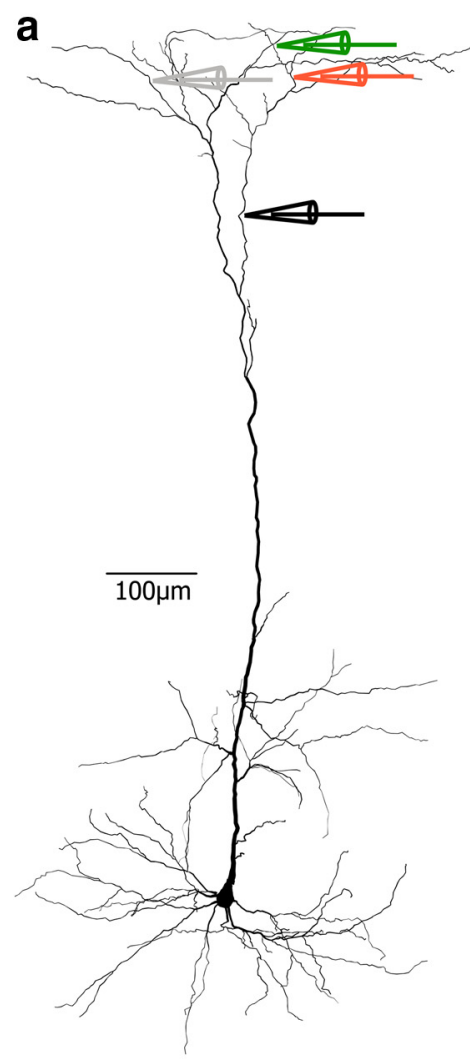

b
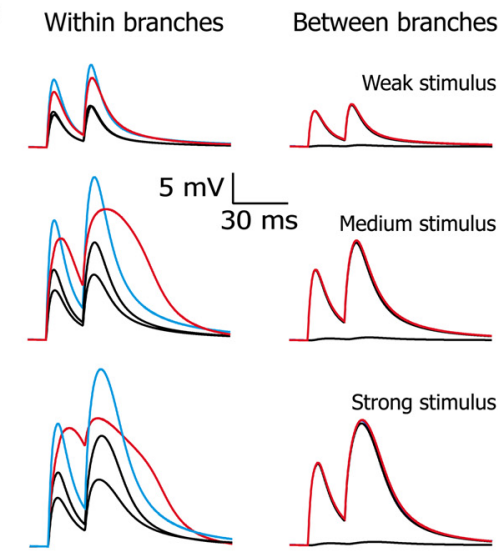

C

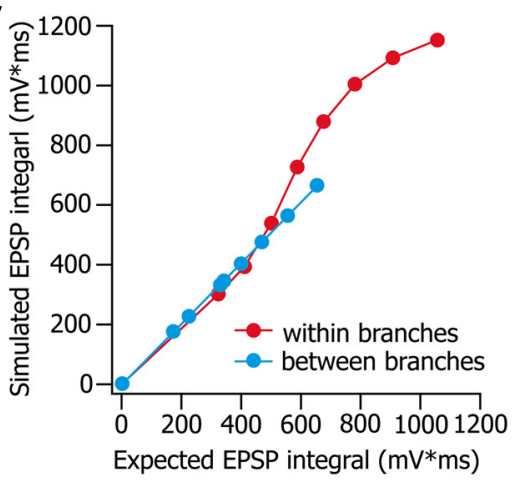

Figure 13. Simulated NMDA spikes within and between dendrite branches. $\boldsymbol{a}$, Reconstruction of a layer 5 pyramidal neuron stained with biocytin, illustrating electrode placement. $\boldsymbol{b}$, A NMDA-like spike was evoked through two distal pipettes (green and orange) after inserting NMDA and AMPA synapses (Larkum et al., 2009) into one of the optimized models (Table 1, cell 5). Left, Integration within branches. First, the distal pipettes (green and orange) were activated separately (black traces) and then simultaneously (red traces). The EPSPs were simulated $150 \mu \mathrm{m}$ below the orange pipette. The blue trace represents the summation of the two individual activations. The summation is shown for weak, medium, and strong stimuli. The distance between the two pipettes at the same branch was $26 \mu \mathrm{m}$. Right, Integration between branches. First, the distal pipettes (gray and orange) were activated separately (black traces) and then simultaneously (red traces). The EPSPs were simulated $150 \mu \mathrm{m}$ below the orange pipette. The summation is shown for weak, medium, and strong stimuli. c, Expected versus actual simulated EPSP intervals are plotted for a range of stimulus intensities for summation within the branch (red line) and between branches (blue line).

Druckmann S, Banitt Y, Gidon A, Schürmann F, Markram H, Segev I (2007) A novel multiple objective optimization framework for constraining conductance-based neuron models by experimental data. Front Neurosci 1:7-18. CrossRef Medline

Druckmann S, Berger TK, Hill S, Schürmann F, Markram H, Segev I (2008) Evaluating automated parameter constraining procedures of neuron models by experimental and surrogate data. Biol Cybern 99:371-379. CrossRef Medline

Druckmann S, Berger TK, Schürmann F, Hill S, Markram H, Segev I (2011) Effective stimuli for constructing reliable neuron models. PLoS Comput Biol 7:e1002133. CrossRef Medline

Foehring RC, Mermelstein PG, Song WJ, Ulrich S, Surmeier DJ (2000) Unique properties of R-type calcium currents in neocortical and neostriatal neurons. J Neurophysiol 84:22252236. Medline

Gold C, Henze DA, Koch C (2007) Using extracellular action potential recordings to constrain compartmental models. J Comput Neurosci 23:39-58. CrossRef Medline

Gurkiewicz M, Korngreen A (2007) A numerical approach to ion channel modelling using whole-cell voltage-clamp recordings and a genetic algorithm. PLoS Comput Biol 3:e169. CrossRef Medline

Hay E, Hill S, Schürmann F, Markram H, Segev I (2011) Models of neocortical layer 5b pyramidal cells capturing a wide range of dendritic and perisomatic active properties. PLoS Comput Biol 7:e1002107. CrossRef Medline

Hodgkin AL, Huxley AF (1952) A quantitative description of membrane current and its application to conduction and excitation in nerve. J Physiol 117:500-544. Medline

Huys QJ, Ahrens MB, Paninski L (2006) Efficient estimation of detailed single-neuron models. J Neurophysiol 96:872-890. CrossRef Medline

Johnston D, Christie BR, Frick A, Gray R, Hoffman DA, Schexnayder LK, Watanabe S, Yuan LL (2003) Active dendrites, potassium channels and synaptic plasticity. Philos Trans R Soc

\section{References}

Akemann W, Knöpfel T (2006) Interaction of $\mathrm{K}_{\mathrm{v}} 3$ potassium channels and resurgent sodium current influences the rate of spontaneous firing of Purkinje neurons. J Neurosci 26:4602-4612. CrossRef Medline

Almog M, Korngreen A (2009) Characterization of voltage-gated $\mathrm{Ca}^{2+}$ conductances in layer 5 neocortical pyramidal neurons from rats. PLoS One 4:e4841. CrossRef Medline

Amitai Y, Friedman A, Connors BW, Gutnick MJ (1993) Regenerative activity in apical dendrites of pyramidal cells in neocortex. Cereb Cortex 3:26-38. CrossRef Medline

Benhassine N, Berger T (2005) Homogeneous distribution of largeconductance calcium-dependent potassium channels on soma and apical dendrite of rat neocortical layer 5 pyramidal neurons. Eur J Neurosci 21:914-926. CrossRef Medline

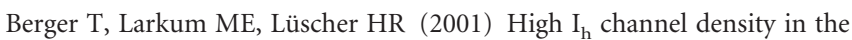
distal apical dendrite of layer $\mathrm{V}$ pyramidal cells increases bidirectional attenuation of EPSPs. J Neurophysiol 85:855-868. Medline

Carnevale NT, Hines ML (2006) The NEURON book. New York: Cambridge UP.

Deister CA, Chan CS, Surmeier DJ, Wilson CJ (2009) Calcium-activated SK channels influence voltage-gated ion channels to determine the precision of firing in globus pallidus neurons. J Neurosci 29:8452-8461. CrossRef Medline

Destexhe A, Babloyantz A, Sejnowski TJ (1993) Ionic mechanisms for intrinsic slow oscillations in thalamic relay neurons. Biophys J 65:15381552. CrossRef Medline
Lond B Biol Sci 358:667-674. CrossRef Medline

Keren N, Peled N, Korngreen A (2005) Constraining compartmental models using multiple voltage recordings and genetic algorithms. J Neurophysiol 94:3730-3742. CrossRef Medline

Keren N, Bar-Yehuda D, Korngreen A (2009) Experimentally guided modelling of dendritic excitability in rat neocortical pyramidal neurones. J Physiol 587:1413-1437. CrossRef Medline

Khaliq ZM, Gouwens NW, Raman IM (2003) The contribution of resurgent sodium current to high-frequency firing in Purkinje neurons: an experimental and modeling study. J Neurosci 23:4899-4912. Medline

Korngreen A, Sakmann B (2000) Voltage-gated $\mathrm{K}^{+}$channels in layer 5 neocortical pyramidal neurones from young rats: subtypes and gradients. J Physiol 525:621-639. CrossRef Medline

Lang DG, Ritchie AK (1990) Tetraethylammonium blockade of apaminsensitive and insensitive $\mathrm{Ca}^{2+}$-activated $\mathrm{K}^{+}$channels in a pituitary cell line. J Physiol 425:117-132. Medline

Larkum ME, Zhu JJ (2002) Signaling of layer 1 and whisker-evoked $\mathrm{Ca}^{2+}$ and $\mathrm{Na}^{+}$action potentials in distal and terminal dendrites of rat neocortical pyramidal neurons in vitro and in vivo. J Neurosci 22:6991-7005. Medline

Larkum ME, Zhu JJ, Sakmann B (1999a) A new cellular mechanism for coupling inputs arriving at different cortical layers. Nature 398:338-341. CrossRef Medline

Larkum ME, Kaiser KM, Sakmann B (1999b) Calcium electrogenesis in distal apical dendrites of layer 5 pyramidal cells at a critical frequency of 
back-propagating action potentials. Proc Natl Acad Sci U S A 96:1460014604. CrossRef Medline

Larkum ME, Zhu JJ, Sakmann B (2001) Dendritic mechanisms underlying the coupling of the dendritic with the axonal action potential initiation zone of adult rat layer 5 pyramidal neurons. J Physiol 533:447-466. CrossRef Medline

Larkum ME, Nevian T, Sandler M, Polsky A, Schiller J (2009) Synaptic integration in tuft dendrites of layer 5 pyramidal neurons: a new unifying principle. Science 325:756-760. CrossRef Medline

London M, Häusser M (2005) Dendritic computation. Annu Rev Neurosci 28:503-532. CrossRef Medline

Magee JC (1999) Dendritic $I_{h}$ normalizes temporal summation in hippocampal CA1 neurons. Nat Neurosci 2:848. CrossRef Medline

Magee JC, Avery RB, Christie BR, Johnston D (1996) Dihydropyridinesensitive, voltage-gated $\mathrm{Ca}^{2+}$ channels contribute to the resting intracellular $\mathrm{Ca}^{2+}$ concentration of hippocampal CA1 pyramidal neurons. J Neurophysiol 76:3460-3470. Medline

Magistretti J, Brevi S, de Curtis M (2000) A blocker-resistant, fast-decaying, intermediate-threshold calcium current in palaeocortical pyramidal neurons. Eur J Neurosci 12:2376-2386. CrossRef Medline

Mainen ZF, Sejnowski TJ (1996) Influence of dendritic structure on firing pattern in model neocortical neurons. Nature 382:363-366. CrossRef Medline

Martina M, Vida I, Jonas P (2000) Distal initiation and active propagation of action potentials in interneuron dendrites. Science 287:295-300. CrossRef Medline

Mercer JN, Chan CS, Tkatch T, Held J, Surmeier DJ (2007) $\mathrm{Na}_{\mathrm{v}} 1.6$ sodium channels are critical to pacemaking and fast spiking in globus pallidus neurons. J Neurosci 27:13552-13566. CrossRef Medline

Migliore M, Shepherd GM (2002) Emerging rules for the distributions of active dendritic conductances. Nat Rev Neurosci 3:362-370. CrossRef Medline

Mitchell M (1996) An introduction to genetic algorithms. Cambridge, MA: MIT.

Pérez-Garci E, Larkum ME, Nevian T (2013) Inhibition of dendritic $\mathrm{Ca}^{2+}$ spikes by $\mathrm{GABA}_{\mathrm{B}}$ receptors in cortical pyramidal neurons is mediated by a direct $\mathrm{G}_{\mathrm{i} / \mathrm{o}}$-beta-subunit interaction with $\mathrm{Ca}_{\mathrm{v}} 1$ channels. J Physiol 591: 1599-1612. CrossRef Medline

Polsky A, Mel BW, Schiller J (2004) Computational subunits in thin dendrites of pyramidal cells. Nat Neurosci 7:621-627. CrossRef Medline
Schaefer AT, Larkum ME, Sakmann B, Roth A (2003) Coincidence detection in pyramidal neurons is tuned by their dendritic branching pattern. J Neurophysiol 89:3143-3154. CrossRef Medline

Schaefer AT, Helmstaedter M, Schmitt AC, Bar-Yehuda D, Almog M, BenPorat H, Sakmann B, Korngreen A (2007) Dendritic voltage-gated $\mathrm{K}^{+}$ conductance gradient in pyramidal neurones of neocortical layer $5 \mathrm{~B}$ from rats. J Physiol 579:737-752. CrossRef Medline

Schiller J, Helmchen F, Sakmann B (1995) Spatial profile of dendritic calcium transients evoked by action potentials in rat neocortical pyramidal neurones. J Physiol 487:583-600. Medline

Schiller J, Schiller Y, Stuart G, Sakmann B (1997) Calcium action potentials restricted to distal apical dendrites of rat neocortical pyramidal neurons. J Physiol 505:605-616. CrossRef Medline

Schiller J, Major G, Koester HJ, Schiller Y (2000) NMDA spikes in basal dendrites of cortical pyramidal neurons. Nature 404:285-289. CrossRef Medline

Storm JF (1987) Action potential repolarization and a fast afterhyperpolarization in rat hippocampal pyramidal cells. J Physiol 385:733759. Medline

Stuart GJ, Sakmann B (1994) Active propagation of somatic action potentials into neocortical pyramidal cell dendrites. Nature 367:69-72. CrossRef Medline

Stuart GJ, Dodt HU, Sakmann B (1993) Patch-clamp recordings from the soma and dendrites of neurons in brain slices using infrared video microscopy. Pflugers Arch 423:511-518. CrossRef Medline

Stuart G, Schiller J, Sakmann B (1997) Action potential initiation and propagation in rat neocortical pyramidal neurons. J Physiol 505:617-632. CrossRef Medline

Sun X, Gu XQ, Haddad GG (2003) Calcium influx via L- and N-type calcium channels activates a transient large-conductance $\mathrm{Ca}^{2+}$-activated $\mathrm{K}^{+}$current in mouse neocortical pyramidal neurons. J Neurosci 23:3639-3648. Medline

Yuste R, Gutnick MJ, Saar D, Delaney KR, Tank DW (1994) $\mathrm{Ca}^{2+}$ accumulations in dendrites of neocortical pyramidal neurons: an apical band and evidence for two functional compartments. Neuron 13:23-43. CrossRef Medline

Zhu JJ (2000) Maturation of layer 5 neocortical pyramidal neurons: amplifying salient layer 1 and layer 4 inputs by $\mathrm{Ca}^{2+}$ action potentials in adult rat tuft dendrites. J Physiol 526:571-587. Medline 